\title{
The Application of Salutogenesis in Hospitals
}

\author{
Christina Dietscher, Ulrike Winter, and Jürgen M. Pelikan
}

\section{Introduction}

Hospitals are traditionally characterized by an orientation to diagnosing, curing, and caring for severe illness episodes in patient careers (and increasingly also for the continuous care for chronic patients at repeated points of contact); hospitals are often life-saving. However, it is no exaggeration to say that hospitals are in many aspects also highly pathogenic. Not only is it the very core business of hospitals to deal with the results of pathogenic or entropic processes in patients (possibly with obstetrics as one exception), but the hospital as a setting also contains specific pathogenic dangers and risks (e.g., nosocomial infections, medical errors, and hospitalization effects), and radical life-saving interventions often need to be performed that have themselves a certain pathogenic potential. Therefore, they need to be precisely targeted, such as an operation or chemotherapy, if they are to produce more benefit than harm, and need to be performed by highly specialized and skilled personnel. For this reason, there is a natural knowledge and power divide between healthcare staff (especially doctors) and their patients, with patients being often resigned to a rather passive role. Health research-

This chapter is a revision and update of work published in Mittelmark, M.B., Sagy, S., Eriksson, M., Bauer, G., Pelikan, J.M., Lindström, B., \& Espnes, G.A. (eds). (2017). The Handbook of Salutogenesis. Springer, Cham. DOI: https://doi.org/10.1007/978-3-319-04600-6.

C. Dietscher $(\triangle)$

Department of Non-Communicable Diseases, Mental Health and Geriatric Medicine, Austrian Ministry of Health, Vienna, Austria e-mail: christina.dietscher@gesundheitsministerium.gv.at

U. Winter

Freelancer, Vienna, Austria

e-mail: uli.winter@chello.at

J. M. Pelikan

University of Vienna, Vienna, Austria

WHO-Collaborating Centre for Health Promotion in Hospitals and Healthcare at the Austrian National Public Health Institute (Gesundheit Österreich GmbH), Vienna, Austria ers have repeatedly stressed the need to actively include patients in healthcare decisions and processes in order to achieve optimum outcomes (Coulter \& Ellins, 2007). In light of the aging of populations and the increasing proportion of patients with long-term chronic conditions, this demand appears more timely than ever.

Informed consent and shared decision-making movements are one reaction to this problem. They demand that patients need to be informed about and consent to treatment options. Yet, this approach is often more a safety belt for medical staff, preventing them from being sued in the case of negative treatment outcomes, rather than a real integration of the patient in decision processes. In addition, the currently predominating culture of prevention (compare Dietscher \& Pelikan, 2016) raises the fear to be sued for preventable medical errors. According to estimates, such errors affect one in ten hospital patients to some degree. In reaction, healthcare personnel recommend medical tests, and perform treatments, that are often not necessary. Gigerenzer and Gray (2011) call this approach "defensive medicine."

Hospital economics often have similar effects. Especially when financing mechanisms are performance-based, medical interventions are sometimes performed according to business plans rather than to meet patient needs (resulting in huge differences in the numbers of medical interventions that are performed in different countries and hospitals), often causing unnecessary risks to patient safety. Furthermore, medical interventions are often performed with a rather short-sighted perspective, not considering long-term implications for the quality of life. When discharged from hospitals after ever-shorter stays, patients often find themselves left alone with, and overwhelmed by, the challenges diseasespecific self-management can pose.

Hospital staff, too, are confronted with many healthrelated stressors. They are among the professional groups with the highest health risks (Eurofound, 2012). These include the exposure to biological, chemical, and nuclear agents, physical strains from lifting patients or working in strenuous postures (such as in surgery), the need to perform 
shift work, having to cope with a high and difficult-to-plan work load, being continuously confronted with suffering and death, having to communicate interprofessionally, interhierarchically and between units, and having to cope with ongoing healthcare reforms.

The result is high fluctuation rates, which in turn confront hospital management with the necessity to maintain, or improve, the quality of services with ever-changing personnel. The situation is not eased by the aging of populations and by the raising of retirement ages. Staff need to perform for more life years than in the past while at the same time the number of patients needing treatment and the complexity of their conditions are also on the rise.

Concerning people in the neighborhood and catchment area, hospitals traditionally do not have that many points of direct contact. However, their mere functioning can have saluto- or pathogenic effects on their surroundings. Hospitals are large consumers of energy and goods; they create traffic and produce potentially dangerous waste, such as toxic wastewater and emissions. Thus, decisions taken by the purchasing department, for example, on buying local and biological food for the canteen, architectonic decisions that may have implications for the amount of energy needed to heat or cool the building, and the quality of waste management systems all contribute to saluto- or pathogenic impacts for people in the nearer or wider neighborhood.

In addition, hospitals are large consumers of healthcare budgets and, as such, use scarce resources on a comparably low number of people. WHO-Euro's current health policy, Health 2020, maintains that "we continue to spend far too little on health promotion and disease prevention compared with treatment. Health 2020 argues strongly that this balance needs to change in favor of upstream interventions to prevent the later human and economic burden of end-stage disease and disability" (WHO, 2013).

Numerous reform concepts have already been initiated from different angles, aiming at improving the salutogenic effects of health services:

- Patients' rights movements have led to the appointment of ombudsmen and patient attorneys. While in principle this is a positive development, a potentially dangerous side effect is a culture of not openly communicating about error in hospitals, by that missing chances for improvement.

- In the wake of the hospital quality movements, the concept of co-production of health was introduced, as healthcare staff became increasingly aware that treatment outcomes are suboptimal without the cooperation of the patients.

- Evidence-based medicine, with its criteria of scientific evidence, staff competencies, and patient preferences, aims at supporting rational healthcare decisions and omitting unnecessary interventions.

- Concepts for integrative care aim at supporting patients through their whole patient journey, not only the rather short hospital stay.

- Supranational agents like the World Health Organization are increasingly concerned about healthcare's ability to tackle non-communicable diseases and have been developing global action plans in which health services are seen as one of many actors who need to cooperate with others.

- Health promotion introduced the concept of empowerment; and the patient education movements introduced the need for (critical) health literacy.

- For hospital staff, there are specific concepts of workplace health promotion.

- For people in the neighborhood and catchment area, concepts like "sustainable" hospitals and "green" hospitals have developed.

- Health-Promoting Hospitals (HPHs) have further strengthened hospitals' community focus by encouraging health-promoting collaborations between hospitals and other organizations, such as schools or enterprises, or by suggesting the use of hospital data to inform decisions on health-promoting community development.

The above-mentioned and other reform movements have been implemented in hospitals to very different degrees. Hospitals are characterized by comparably high levels of hierarchy, and compared to the influence of the health professionals, management has a limited role. This organizational constellation has been coined the "professional bureaucracy" (Mintzberg, 2012). Because of these characteristics, hospital innovations very much depend on the actual motivation and behavior of healthcare professionals. Therefore, it is decisive to convince and train professionals (not only management) to achieve change. On an organizational level, following the German sociologist Niklas Luhmann (2011), it is decisions that reproduceand can change - an organization. The consequence of this theory for altering organizations is that changes, in order to be effective and sustainable, have to be enacted by the everyday decisions of the members of the organization itself, but have to be enabled by supporting structures and cultures (Pelikan et al., 2014). Therefore, any reform proposal coming from outside needs to address and to relate to the specific way an organization takes and supports decisions.

We apply this perspective in asking not only how hospitals can be made less pathogenic - what most of the abovementioned reform movements aim for-but how they could actually be made more salutogenic settings. 


\section{A General Salutogenic Orientation on Hospitals}

In light of the above, it appears obvious that the introduction of salutogenesis provides a challenge and contradiction to the established practice of hospital healthcare. In the following, we provide some suggestions on how a salutogenic hospital could look like and what dimensions it would comprise, drawing on our understanding of Antonovsky's salutogenic orientation and model, as well as on the sense of coherence, and on our background in HPHs.

Antonovsky's (1996) salutogenic orientation introduces a resource-oriented-instead of risk-oriented-perspective on the maintenance, restoration, or improvement of health. To promote health, Antonovsky demands an orientation to salutary factors which allow people to remain on, or move further toward, the health side of what he describes as the health-disease continuum, by allowing them to handle well the stressors they are doggedly confronted with:

This orientation, which should be reflected in both research and action, should refer to all aspects of a person and to everybody, no matter where they are on the health disease continuum: A salutogenic orientation, then, as the basis for health promotion, directs both research and action efforts to encompass all persons, wherever they are on the continuum (Antonovsky, 1996, p. 14).

Taking this perspective seriously would require a rather radically changed perspective not only on current hospital healthcare practice, but also on education of healthcare professionals and on research.

First, the risk and deficit-oriented approach that is now common in healthcare would have to be replaced or at least complemented by a thoroughly resource-oriented approach. In relation to hospital patients, this would mean a resourcestrengthening approach from the first point of contact until discharge, focusing not only on symptoms, risks, and deficits but also on maintaining, using, and improving the resources that can support recovery or at least delay the progression of disease. Since salutogenesis refers to "all aspects of a person," this perspective needs to encompass health and resources for health in a comprehensive, somatopsycho-social sense. Accordingly, clinical research and care would have to expand from the best available medical care to asking which patients' physical, mental, and social resources (such as self-care, personal health beliefs, or social networks) are most helpful to support healing. Another important research question is how these resources can be activated.

Furthermore, encompassing "all persons, wherever they are on the health-disease continuum," would imply that all patients, no matter whether they are just there for a routine check-up or in palliative care, can and have to be addressed in a salutogenic way, focusing on, and strengthening, the resources they (still) have.
And of course the resource-oriented approach would also have to be applied to hospital staff by ensuring that they have the resources available they need for performing their job. This could, for example, be achieved by a comprehensive workplace health promotion approach.

For neighborhood and catchment areas, the resourceoriented approach would mean to transform hospitals into health resources for their communities, for example, by offering easily accessible and easy-to-understand health information in a hospital library, on the hospital website, or a hospital TV program, or by collaborating in joint healthoriented projects with local schools, enterprises, or administrations.

Second, in the spirit of "do no harm," it would be necessary to consider how far standard diagnostic and therapeutic interventions actually represent health resources-or rather risks or stressors to the health of patients (Ventegodt, Kandel, $\&$ Merrick, 2007). One option to avoid unnecessary stressors to health is by not applying interventions if the potential harm can be expected to outweigh the potential benefits. This could be the case, for example, for some CT scans because of the high radiation dose they incur. A specific campaign to support the aim to eliminate unnecessary or potentially harmful treatment was developed in the USA under the title "Choosing wisely" (see http://www.choosingwisely.org ; visited on July 28, 2015).

For healthcare staff, doing no harm has much in common with occupational health and safety management. It is important to identify the relevant stressors, for example, by using health circles (Aust \& Ducki, 2004). Wherever possible, identified stressors should be eliminated or reduced. For example, communication problems between units can be improved by changing communication routines. For stressors that cannot be eliminated, adequate compensation should be provided. For example, the continuous confrontation of staff with suffering and death is endemic to hospitals, but its effect on staff can be eased by psychological interventions or by an organizational policy on how to deal with emotional strain. Also, there will always be the need for shift work in hospitals, but much can be done to improve work organization in the sense of a good work-life balance, an approach that has also become known as "family-friendly workplace." A salutogenic perspective might help to identify and address these and other staff-related stressors more systematically.

For catchment areas and communities, finally, avoiding harm can be achieved by a safer handling of hazardous hospital wastes. For example, potentially harmful residues of medical drugs, including antibiotics, hormones, or cytostatic agents, constantly get into the environment by way of medical wastewaters. As more and more treatments are being carried out in day clinics, those drugs also increasingly pass through the plumbing systems of regular households and might finally end up in the ecosystem. 
From our comprehensive perspective on salutogenesisencompassing patients, staff, and community citizens as target groups-follows that salutogenic interventions are not limited to interventions in persons. Such interventions include not least interventions to improve the physical hospital design. This can include ergonomics for staff or, concerning patients, quiet rooms (Hasfeldt et al., 2014), as well as naturally aired and lighted rooms. Light was, for example, found to make a difference on mortality after myocardial infarction (compare the study "dying in the dark" (Beauchemin \& Hays, 1998)). A summary of the salutogenic effects of healthcare design (although without explicitly referring to salutogenesis) can be found in Ulrich, Berry, Quan, and Parish (Ulrich et al., 2010).

\section{Sense of Coherence}

Antonovsky's comprehensive salutogenic model puts great emphasis on characteristics that enable people to deal with different types of stressors. This seems particularly important in light of the available evidence from psychoneuroimmunology research on the impacts of stress on physical health (compare Kusnekov \& Anisman, 2013). In hospitals, an orientation at this approach would demand a focus on reducing specific healthcare-related stressors for those persons who are exposed to hospitals. Furthermore, their stresscoping competences and resources need to be strengthened.

The sense of coherence can be understood as the most specific and focused way to operationalize Antonovsky's concept of salutogenesis. It implies the importance of three dimensions for successfully coping with challenges: these are comprehensibility, manageability, and meaningfulness of life. It seems that these dimensions also relate to the functioning of the human brain (compare Rock, 2008). Attempting at reducing possible stress by improving comprehensibility, manageability, and meaningfulness of life has specific consequences for the design and organization of health services, as well as for the content of healthcare interventions.

Studies on health literacy - the ability to find, understand, appraise, and apply health-related information-demonstrate that comprehensibility of healthcare tasks is difficult for many patients (Sørensen et al., 2015). A lot of verbal and written healthcare communication is based on medical jargon which makes it difficult for patients to detect the meaning of what they are told or of what they read. An orientation to the sense of coherence would require that health information be offered in an understandable way, in other words, by using plain language and writing in short sentences, and breaking content down into digestible junks of information. Written information and interpreting services should also be available in the languages of most patients. Furthermore, comprehensibility can be supported by healthcare design, for example, by providing easy-to-read signage (Rudd \& Anderson, 2006).

Healthcare staff, too, can profit from an increased orientation to comprehensibility. By using communication tools like teach-back (letting patients explain what they understand in their own words), staff can develop a better understanding of their patients' communication needs (Pelikan \& Dietscher, 2015). In some cases, it may be important to improve the comprehensibility - or disease-specific literacy —of healthcare personnel before they can properly support their patients. For example, Gigerenzer (2014) found that many medical doctors are not sufficiently trained to correctly interpret healthcare statistics. They may also be deliberately misled in interpreting findings by the way study findings are presented. The result is an overestimation of the benefits of medical diagnostic and therapeutic interventions, and an underestimation of the related potential harm, which has considerable implications for treatment recommendations. On the basis of these and similar findings, the Harding Centre for Risk Literacy developed a specific format-so-called fact boxes-for presenting medical information in an easy-to-understand way. The fact boxes give absolute figures on potential benefits and potential harms of diagnostic or treatment interventions, instead of difficult-to-interpret data formats like relative risks on potential benefits alone. This information provides the grounds for well-informed healthcare decision-making in a partnership between professionals and patients (https:// www.harding-center.mpg.de/en/health-information ; visited February 25, 2015).

An increased orientation to the manageability aspect of sense of coherence would mean that patients, especially those with chronic diseases (and relatives or other caregivers), are empowered as much as possible to take care of their own condition, during and between hospital stays. For those who have problems with self-management, specific support should be available, for example, in the form of case management.

For staff, an orientation to manageability would also mean a perception of one's work life as malleable if work conditions are felt to be burdensome. Staff should be encouraged to make suggestions for improvements of the work flow, and there should be flexible options to support staff with acute problems (e.g., having to care for a family member at home).

And, for people in the hospital neighborhood and catchment area, an orientation to manageability would mean that the hospital offers publicly available information about the self-management of disease, and of health enhancement, for example, via its website, at health fairs, or in cooperation with other stakeholders. 
Meaningfulness, finally, can be supported by psychological or pastoral interventions that enable people to make sense of their situation as a patient or staff member. While there may be more technical solutions for improving comprehensibility and manageability, supporting meaningfulness seems to be a rather individualized process which has to be mainly achieved in person-to-person interaction.

All three aspects of the sense of coherence can be addressed in relation to challenges posed by the routine functioning of the hospital itself-interventions would then aim at improving comprehensibility, manageability, and meaningfulness of being a patient or staff member. But interventions can also address the challenges of life in general. This may be adequate for patients with long-term conditions as well as for staff whose workability suffers from personal problems.

And, while a general salutogenic orientation of hospital structures and processes might be supportive for all those in contact with the hospital, people with a weak sense of coherence may need further specific compensatory support (providing help to understanding, managing, and sense-making).

\section{Developing Organizational Capacities for Salutogenesis}

From a quality perspective, and salutogenesis should be introduced into hospitals as a specific dimension of quality, it follows that salutogenic processes need to be supported by salutogenic structures in order to produce desired salutogenic outcomes. Salutogenesis should ideally be considered an organizational principle the implementation of which is supported by adequate organizational structures and capacities. Such capacities include leadership support, clear organizational responsibilities for salutogenesis, trained and experienced staff, an earmarked budget, and the inclusion of criteria and indicators for salutogenesis into continuous monitoring and improvement processes for which support from quality management might be a useful lever (Pelikan et al., 2001; Röthlin et al., 2015). The existence of such capacities would enable a continuous improvement of the salutogenic orientation of the overall daily functioning of hospitals as the centers of modern healthcare delivery systems. In addition, hospitals can support research on the role of salutogenesis in patient treatment, in designing workplaces for their staff, and in working with people in neighborhoods and catchment areas. Not least, they can contribute to teaching and training healthcare professionals to perform salutogenic healthcare interventions.

\section{Research on Salutogenesis as Applied to Hospitals}

We will now contrast the "salutogenic hospital blueprint" that we outlined above with the findings of a literature search on salutogenesis in hospitals that we performed in Medline and PubMed. Our main research question here is: how far does the available literature already refer to concepts of salutogenesis in relation to hospital structures or processeswhich areas are covered, which are not? And do new areas emerge from the literature that could be used to further develop the blueprint?

We used Reference Manager as search tool to identify articles whose titles or abstracts contained a combination of one or more of the keywords salutogenesis, salutogenic, sense of coherence, or general/generalized resistance resources, with the keywords hospital, patient, doctor, or nurse, and which had been published until September 2014.

The main inclusion criterion was that papers retrieved should refer to salutogenesis or specific concepts like the Sense of Coherence (SOC) or generalized resistance resources in relation to hospital structures or processes. Papers were excluded if they met one or more of the following exclusion criteria:

- Clinical study with a focus on the impact of salutogenesis/SOC on the etiology of specific diseases, or other clinical study, without explicit referral to hospital characteristics or interventions.

- Focus on other healthcare settings than hospitals.

- Study on validation of measurement tool without relation to salutogenic impacts of hospital characteristics or interventions.

- Lack of conclusions in relation to salutogenesis.

- Abstract not available.

Of all 532 abstracts retrieved, 354 were excluded because they met one of the defined exclusion criteria (see Table 37.1).

Table 37.1 Defined exclusion criteria, number and percent of excluded papers per criterion

\begin{tabular}{l|l|l}
\hline Exclusion criteria & $\begin{array}{l}\text { Number } \\
\text { papers }\end{array}$ & $\begin{array}{l}\text { Percent } \\
\text { papers }\end{array}$ \\
\hline $\begin{array}{l}\text { Clinical study with a focus on the impact of } \\
\text { salutogenesis/SOC on the etiology of specific } \\
\text { diseases, or other clinical study without } \\
\text { explicit relation to hospital characteristics or } \\
\text { interventions }\end{array}$ & 169 & 47.7 \\
\hline Focus on other healthcare setting than hospital & 142 & 40 \\
\hline $\begin{array}{l}\text { No conclusions in relation to salutogenesis } \\
\text { were presented }\end{array}$ & 29 & 8.19 \\
\hline $\begin{array}{l}\text { Study on validation of measurement tool } \\
\text { without }\end{array}$ & 11 & 3 \\
\hline Abstract not available & 3 & 1 \\
\hline Total & 354 & 100.00 \\
\hline
\end{tabular}


Table 37.2 Search results

\begin{tabular}{l|l|l|l|l}
\hline Keyword combination & Retrieved & Excluded & Focus on patients & Focus on staff \\
\hline Hospital + salutogenesis & 2 & 0 & 1 & 1 \\
\hline Hospital + salutogenic & 16 & 6 & 6 & 4 \\
\hline Hospital + SOC & 122 & 68 & 47 & 7 \\
\hline Hospital + GRRs & 0 & 0 & 0 & 0 \\
\hline Patients + salutogenesis & 35 & 22 & 13 & 0 \\
\hline Patients + salutogenic & 15 & 12 & 3 & 0 \\
\hline Patients + SOC & 310 & 224 & 84 & 2 \\
\hline Patients + GRRs & 0 & 0 & 0 & 0 \\
\hline Nurses + salutogenesis & 1 & 1 & 0 & 0 \\
\hline Nurses + salutogenic & 8 & 6 & 0 & 2 \\
\hline Nurses + SOC & 18 & 11 & 0 & 7 \\
\hline Nurses + GRRs & 0 & 0 & 0 & 0 \\
\hline Doctors + salutogenesis & 2 & 1 & 0 & 1 \\
\hline Doctors + salutogenic & 0 & 0 & 0 & 0 \\
\hline Doctors + SOC & 3 & 3 & 0 & 0 \\
\hline Doctors + GRRs & 0 & 0 & 0 & 0 \\
\hline Total & 532 & 354 & 154 & 24 \\
\hline
\end{tabular}

The majority of excluded studies focused on the role of salutogenesis in the etiology of diseases and had no relation to healthcare as such (169 papers or $48 \%$ of all eliminated papers); 142 papers (40\%) were excluded because they did not refer to hospitals but for example to patients in long-term care. Eight percent were excluded because their findings were not used to draw conclusions of relevance to salutogenesis. Three percent were excluded because they described the validation of measurement tools, and $1 \%$ of papers could not be further assessed because no (English) abstract was available.

Of the remaining 178 papers, 154 focused on patients and 24 on hospital staff; 158 (89\%) focused on the sense of coherence (of these, 140 papers on patients and 18 on staff), 20 papers on a general, usually rather unspecified and normative salutogenic orientation (of these, 14 papers on patients and 6 papers on staff), and only 2 papers focused on generalized resistance resources (compare Table 37.2).

Abstracts of the included papers were content-analyzed in order to get a deeper understanding of what aspects of salutogenesis, the salutogenic model, and the sense of coherence or generalized resistance resources they covered in relation to hospital structures, processes, and target groups. On the basis of the results, a narrative review was produced.

\section{Salutogenesis in Relation to Hospital Patients}

Hundred and fifty-four of the included papers addressed hospital patients. The retrieved papers were published between 1991 and 2014. The majority of papers (80\%) were pub-
Table 37.3 Geographic areas from which papers on salutogenesis and hospital patients were published

\begin{tabular}{l|l|l}
\hline Region & Number papers & Percent papers \\
\hline Europe & 124 & 80.52 \\
\hline Asia including Israel & 14 & 9.09 \\
\hline North America & 7 & 4.55 \\
\hline Australia & 6 & 3.90 \\
\hline South America & 3 & 1.95 \\
\hline Total & 154 & 100.00 \\
\hline
\end{tabular}

lished by European authors, with Sweden (59 papers), Germany (14 papers), Norway (10 papers), and Switzerland (8 papers) as the top countries. Nine percent of papers were from Asia (including Israel), 5\% from North America, $4 \%$ from Australia, and 2\% from South America (Table 37.3). Over the years, a slight rise of interest in other geographical areas, for example, in China, Japan, Brazil, and a few Eastern European countries was observed.

Over time, a visible increase of publications can be observed. Only $5 \%$ of the 154 papers had been published in the first 5 years (1991-1995) of the observation period, about $16 \%$ of papers respectively were published in the following two 5-year periods, and the percentage went considerably up to $28 \%$ in the next 5-year phase (2006-2010), and rose to $34 \%$ of papers for the period 2011-2015 (Table 37.4).

Eighty-one percent of the 154 patient-related papers refer to patients with specific clinical diagnoses. The majority of these are on frequent, severe, and chronic diseases such as heart diseases $(22 \%)$, cancers $(15 \%)$, severe mental health problems (14\%), or diabetes (7\%). Some papers also address patients with chronic conditions in general, or with rare diseases, such as ménières and cystic fibrosis. 
Table 37.4 Distribution of publications over time

\begin{tabular}{|c|c|c|c|}
\hline Years & $\begin{array}{l}\text { Number } \\
\text { publications }\end{array}$ & $\begin{array}{l}\text { Percent } \\
\text { publications }\end{array}$ & $\begin{array}{l}\text { Percent publications in } \\
5 \text {-year-periods }\end{array}$ \\
\hline 1991 & 1 & 0.65 & \multirow[t]{5}{*}{5.19} \\
\hline 1992 & 2 & 1.30 & \\
\hline 1993 & 0 & 0.00 & \\
\hline 1994 & 2 & 1.30 & \\
\hline 1995 & 3 & 1.95 & \\
\hline 1996 & 4 & 2.60 & \multirow[t]{5}{*}{15.58} \\
\hline 1997 & 2 & 1.30 & \\
\hline 1998 & 3 & 1.95 & \\
\hline 1999 & 10 & 6.49 & \\
\hline 2000 & 5 & 3.25 & \\
\hline 2001 & 4 & 2.60 & \multirow[t]{5}{*}{16.23} \\
\hline 2002 & 3 & 1.95 & \\
\hline 2003 & 5 & 3.25 & \\
\hline 2004 & 5 & 3.25 & \\
\hline 2005 & 8 & 5.19 & \\
\hline 2006 & 4 & 2.60 & \multirow[t]{5}{*}{28.57} \\
\hline 2007 & 13 & 8.44 & \\
\hline 2008 & 9 & 5.84 & \\
\hline 2009 & 10 & 6.49 & \\
\hline 2010 & 8 & 5.19 & \\
\hline 2011 & 15 & 9.74 & \multirow[t]{4}{*}{34.42} \\
\hline 2012 & 19 & 12.34 & \\
\hline 2013 & 13 & 8.44 & \\
\hline 2014 & 6 & 3.90 & \\
\hline 24 & 154 & 100.00 & 100.00 \\
\hline
\end{tabular}

Table 37.5 Clinical diagnoses related to salutogenesis and hospital patients in the literature

\begin{tabular}{l|l|l}
\hline Patients & $\begin{array}{l}\text { Number } \\
\text { publications }\end{array}$ & $\begin{array}{l}\text { Percent } \\
\text { publications }\end{array}$ \\
\hline Heart diseases & 28 & 22.40 \\
\hline Cancers & 19 & 15.20 \\
\hline Mental health/illness & 18 & 14.40 \\
\hline $\begin{array}{l}\text { Specific care units (e.g., ICUs, } \\
\text { palliative care units) }\end{array}$ & 10 & 8.00 \\
\hline Diabetes & 9 & \\
\hline Orthopedic diseases & 8 & 7.20 \\
\hline Pregnancy and conception & 6 & 6.40 \\
\hline Autoimmune diseases & 5 & 4.80 \\
\hline Surgery & 4 & 4.00 \\
\hline Kidney diseases & 4 & 3.20 \\
\hline Rare diseases & 4 & 3.20 \\
\hline $\begin{array}{l}\text { Degenerative neurological } \\
\text { conditions }\end{array}$ & 3 & 3.20 \\
\hline AIDS & & 2.40 \\
\hline Digestive system diseases & 2 & 1.60 \\
\hline Side effects of diseases & 1 & 1.60 \\
\hline Other diseases & 2 & 0.80 \\
\hline & 125 & 1.60 \\
\hline
\end{tabular}

Twelve percent of papers address patients more generally (e.g., "patients of a general hospital"), and the remaining 7\% focus on the salutogenesis of family caregivers, usually in relation to severe illnesses such as cancers (Table 37.5).

\section{Which Concepts of Salutogenesis Are Referred to?}

As was to be expected, the most widely used of Antonovsky's concepts in relation to hospital patients is the sense of coherence ( $91 \%$ of papers). A minority of the related studies apply a qualitative approach, using the SOC dimensions to structure analyses of qualitative data, such as data on patient experiences. Most of the identified studies describe quantitative measurements and analyses of the SOC (either by 29-item, 13-item, or 3-item scales). SOC scores are often related to patients' self-perceived symptom severity, diseaserelated quality of life, subjective well-being, mental comorbidities of somatic diseases, patient satisfaction, or self-care and coping abilities. Furthermore, some studies test their predictive value in relation to the progress of disease.

\section{The SOC in Relation to Physical Symptoms}

Among the patient-related papers, the majority focus on patients with specific somatic diseases, and again a large part of these cover interrelations between the SOC and physical health.

Several papers reflect on the potential impact of the SOC on self-rated health, pain perceptions, symptom severity, treatment outcomes, and physical functionality in patients. Typically, these papers test the hypothesis that stronger SOC scores are related to better subjective health, treatment outcomes, and functionality.

Concerning self-rated health, this hypothesis was confirmed for self-rated health in patients after myocardial infarction (Gerber et al., 2009) and for pain severity (Barthelsson et al., 2011; Cederlund et al., 2010; Hall-Lord et al., 1999; Karlsson et al., 1999). Concerning the severity of other symptoms, Ahola et al. (2010) and Richardson et al. (2001) suggest that stronger SOC scores are related to lower $\mathrm{HbA1c}$ values in diabetic patients, and Bergman et al. (2009) report less angina attacks in heart patients with stronger SOC scores. Li et al. (2015) describe negative correlations between stronger SOC scores, symptom duration, and symptom severity in general, and Tschan et al. (2011) see a reduced likeliness of developing secondary somatoform dizziness after vestibular disease in patients with stronger SOC.

In relation to treatment outcomes, Ristner et al. (2000) identify a weak SOC as a risk factor for suboptimal treatment outcomes after orthopedic injuries. And there are also positive interrelations between SOC scores and physical functionality. For example, Li et al. (2015) detect interrelations between the SOC and daily-life impairment in patients and Schult et al. (2000) describe weak but significant correlations between the SOC and the ability of pain patients to perform daily activities. 
Overall, authors argue that the positive effects of the SOC found in the above-listed studies can either be explained by moderating effects of good mental health (which is typically related to stronger SOC scores) or by better disease-specific self-management of patients with stronger SOC scores, or by a combination of both. These arguments seem to be supported by the fact that the literature reports hardly any findings on interrelations between SOC scores and the severity of diseases or symptoms that do not appear to be directly amenable by self-management or good mental health. For example, in a study on Parkinson patients, Pusswald et al. (2009) could not detect any positive correlations between SOC and somatic health.

In contrast to the idea of the SOC being a stable construct in adults, some longitudinal studies that involved SOC measurements at different points in time (e.g., at hospital admission and at later stages) suggest that the SOC can change over time. For example, according to Bergman et al. (2011), the SOC may decrease after a first-time myocardial infarction. However, the general perception is that SOC values return to the level before the onset of disease when symptoms decrease (see e.g., Berg \& Kononova, 2009).

\section{The SOC in Relation to Mental Symptoms, Quality of Life, and Patient Satisfaction}

Studies on the SOC and mental health can be divided into two groups. One comprises papers studying the SOC in relation to mental diseases such as major depression (e.g., Skarsater et al., 2005), suicidality (Sjostrom et al., 2012), schizophrenia (Eklund et al., 2004; Gassmann et al., 2013), or delusional diseases (Bergstein et al., 2008). The other group consists of papers assessing the SOC in relation to mental comorbidities of somatic diseases and issues. These include cancers (Ezer et al., 2012; Forsberg \& Bjorvell, 1996; Langius \& Lind, 1995; Siglen et al., 2007), myocardial infarction (Benyamini et al., 2013), heart transplantation (Ruzyczka et al., 2011), lumbar spinal stenosis (Sinikallio et al., 2006), Morbus Parkinson (Pusswald et al., 2009), kidney diseases (e.g., Klang et al., 1996), rheumatoid arthritis (Buchi et al., 1998), systemic sclerosis (Hyphantis et al., 2007), traumatic child birth experiences (Stramrood et al., 2011), critical accidents (Schnyder et al., 2000), and critical diseases in general (Fok et al., 2005).

Papers overall (though not in unison) conclude that weaker SOC scores are related to more severe mental disorders or mental comorbidities. For example, Wang et al. (2012) identify a strong SOC as a counter-indicator for anxiety and depression in adolescent heart patients. According to studies on uremic patients (Klang et al., 1996) and on cancer patients (Gustavsson-Lilius et al., 2012), weaker
SOC scores are related to higher levels of anxieties or demoralization (Boscaglia \& Clarke, 2007). With regard to diabetic patients, Wikblad and Montin (1992) conclude that weaker SOC scores are related to lower self-esteem. Some longitudinal studies that assess patients' SOC at different points in time typically conclude, similar to longitudinal studies on the interrelation between the SOC and physical symptoms, that the SOC may change over time, depending on the patients' mental health conditions. For example, in a study on patients with major depression, Skarsater et al. (2005) note that the SOC increases significantly when patients recover. Similarly, Bergstein et al. (2008) point out that the SOC is reduced during phases of remission in delusional patients.

Both in relation to somatic and mental disorders, the literature is quite clear about positive effects of stronger SOC scores on patients' quality of life. One possible explanation might be that the SOC functions as a moderator between psychological distress and health-related quality of life, as suggested by Hyphantis et al. (2011) in a study on patients suffering from systemic Lupus erythematosus. Positive interrelations between the SOC and quality of life are reported for numerous conditions. These include critically ill groups of patients in general (Fok et al., 2005), heart conditions (Bruscia et al., 2008; Norekval et al., 2010; Ruzyczka et al., 2011; Silarova et al., 2012), cancers (Ding et al., 2013; Drabe et al., 2015; Forsberg et al., 1996; Henoch et al., 2007; Mizuno et al., 2009; Paika et al., 2010), and hematopoietic stem cell transplantation (Pillay et al., 2014). Few papers focus on the quality of life in patients with rare diseases. An example is the study by Soderman et al. (2001) on Meniere's disease. This too confirms the positive relation between the SOC and patients' quality of life.

Furthermore, the SOC is also described as being positively related to patient satisfaction (Larsson, 1999; Tistad et al., 2012). Dubs (1999) offers a complex model in which salutogenesis is understood as one factor to explain patient satisfaction after surgery. And Veenstra and Hofoss (2003) identify the SOC as the most important patient-related factor in relation to patients' perception of information received while in the hospital.

\section{The SOC, Adjustment to Disease, Self- Management, and Adherence to Treatment}

Another outcome of interest is the relation of the SOC to patients' ability to adjust to a disease, to take responsibility for their self-care or self-management, and to adhere to treatment recommendations, especially in relation to chronic diseases that require an active participation of patients in relation to maintaining their condition. 
Concerning adjustment to disease, published findings include positive effects of the SOC in relation to myocardial infarction (Drory et al., 1999) and ostomy surgery (Nordstrom \& Lutzen, 1995).

Concerning self-management and adherence to treatment too, the available literature widely suggests positive effects of stronger SOC scores in relation to numerous conditions. For example, Helvik et al. (2012) and Soderhamn et al. (2008) describe positive relations between the SOC and the self-care abilities of elderly patients in general, Spadoti Dantas et al. (2014) report positive links to coping strategies in patients with overall chronic diseases, Ahola et al. (2012) conclude that stronger SOC scores in female diabetes patients are related to healthier food choices, and to more exercise in male diabetes patients. According to Pusswald et al. (2009), the SOC is related to the coping abilities of Parkinson's disease patients, while Silarova et al. (2013) describe weak SOC scores as a risk factor for limited health-related behaviors in heart patients, and Myers et al. (2011) suggest relations to patients' level of leisure-time activities after myocardial infarction. Langius et al. (1994) identify the SOC as related to the functioning and rehabilitation after oral and pharyngeal cancer, Kenne et al. (2013) note relations between the SOC and coping in women with breast cancer, and Stromsvik et al. (2007) use the SOC theory to discuss their findings on the living experiences of Swedish men with multiple endocrine neoplasia. Cederfjall et al. (2002) detect relations between weak SOC scores and non-adherence in HIV patients. Warwick et al. (2010) conclude that a better understanding of the SOC may be helpful to support symptom monitoring and self-care in patients suffering from chronic obstructive pulmonary disease. Sjostrom et al. (2004) conclude that the SOC is important for pregnant women's ability to adjust to unforeseen events in relation to their condition.

Contradictive to these findings, one study on the associations between psychosocial factors and outcomes of physiotherapy reports no relations between the SOC and motivation (Lohmann et al., 2011).

\section{The SOC and Social Outcomes}

A small number of studies focus not only on the relations between the SOC, clinical symptoms, and subjective quality of life but also on relations between the SOC and social outcomes. These include school achievements in adolescents with congenital heart disease (Apers et al., 2013) and experiences of stigma in mental health patients (Lundberg et al., 2009). Papers typically conclude that weaker SOC scores are related to higher risks of experiencing undesired outcomes (such as low school achievement or high levels of stigma).

\section{The SOC and Positive Health}

Not surprisingly given the hospital context of this paper, most of the studies retrieved on the SOC and hospital patients are disease related. Only few studies use salutogenesis concepts such as the SOC to actually explain positive health. Examples are studies on healthy aging, respectively, good health in later life by Gilhooly et al. (2007) and Schneider et al. (2004). Findings suggest positive effects of stronger SOC scores.

\section{The SOC in Relation to Gender, Age, and Socioeconomic Status}

The few studies that differentiate between male and female patients typically find weaker SOC scores in females as compared to males with the same diagnosis and symptom severity (e.g., Bergsten et al., 2011; Cederfjall et al., 2001; Lithner et al., 2012; Torrati et al., 2010; Wrzesniewski \& Wlodarczyk, 2012). Furthermore, literature suggests that the dimensions of the SOC may be of different relevance to men and women. According to a study on patients with cystic fibrosis by Bergsten et al. (2011), males are at higher risk for mental illhealth if they score weak on comprehensibility while females have higher risks if they score weak on manageability. With regard to patients of different socioeconomic status and different ethnicity, Silarova et al. (2013) report that members of more disadvantaged groups have weaker SOC scores. Both gender- and status-specific findings suggest that the development of individual levels of SOC may be dependent on restrictions experienced in relation to gender or socioeconomic status.

\section{The SOC in Relation to Patients' Family Members}

Caring family members-especially those of patients with severe and life-threatening diseases-and relations between their SOC, quality of life, mental health, and well-being are also a frequent theme in patient-related studies. For example, Jaracz et al. (2012) and Larson et al. (2005) report on relations between the SOC, quality of life and the burden of caregivers after stroke. Caap-Ahlgren and Dehlin (2002) focus on family members of Parkinson's disease patients. Drabe et al. (2015), Ezer et al. (2006), Gudmundsdottir et al. (2011), Khanjari et al. (2012), Schmitt et al. (2008), Tang et al. (2013), Tzuh and Li (2008), and Yang et al. (2012) investigate the situation and adjustment of caregivers and family members of cancer patients. 
The literature generally confirms that a stronger SOC of family members reduces their risks for and levels of developing mental comorbidities in relation to taking care of an ill family member (e.g., Gudmundsdottir et al., 2011), and positive effects of strong SOC scores on the quality of life of caring family members are also described (e.g., Ezer et al., 2006).

\section{Salutogenesis in General and the Salutogenic Model}

Less than $10 \%$ of the papers retrieved referred either to Antonovsky's comprehensive salutogenic model or to salutogenesis in general. Tishelman et al. (1991) suggest the salutogenic model as a framework for studying and supporting cancer patients. Wikblad and Montin (1992) use it to identify the caring needs of diabetes patients. When salutogenesis is referred to in more general terms, the concept typically remains rather vague or normative. For example, in a paper by Ventegodt, Thegler, et al. (2007), salutogenesis is described "as the process exactly the opposite of pathogenesis" (Ventegodt, Thegler, et al., 2007, p. 306), or authors claim "salutogenic effects" of suggested interventions, such as relaxation training during pregnancy (Fink et al., 2012). Berger (2003) states that the theory of salutogenesis with its search for health-preserving factors can support the strengthening of patient's self-healing powers by identifying healthy parts, and Onega (1991) understands salutogenesis as a guiding concept for psychiatric care. Referrals to salutogenesis with a slightly esoteric touch can also be found in studies on so-called holistic care (e.g., Ventegodt et al., 2006).

\section{Salutogenesis and Impacts of the Hospital Setting on Patients}

In the sense of a whole-systems approach, another, still rather small strand of research focuses on salutogenesis in relation to the routine processes and physical surroundings of hospitals. For example, one paper by Hasfeldt et al. (2014) focuses on the impact of noise in ICU wards on patient experiences. Results indicate that a weaker SOC is related to higher perceived noise and to higher patient stress levels.

Additional papers on effects of the hospital setting that were identified by freehand search include a synthesis of the evidence of effects of healthcare design on health (Ulrich et al., 2010). Findings suggest that design is a relevant resource for salutogenic processes. More explicitly, Dilani and Armstrong (2008) bring together the concepts of salutogenesis and design, focusing on how physical environments can support understandability (e.g., by clear signage), manageability (e.g., by providing architectonic features that sup- port functional independence), and meaningfulness (e.g., by providing areas for relaxation).

\section{Implications for Salutogenic Patient- Oriented Interventions}

What consequences for supporting patients did the researchers draw from their findings? Basically, five areas of interventions can be distinguished and will be described in more detail in the following. These are: to use the SOC as a diagnostic tool; to adapt treatment schemes to compensate for a weak SOC, or to improve the SOC; to strengthen patient self-management; to support caring family members; and to adapt hospital structures and routines. Overall, hospital nurses are most often suggested as those who should perform these interventions.

\section{Using the SOC as a Diagnostic Tool}

The most widely drawn conclusion from studies on patients and salutogenesis, over a wide spectrum of diseases, is that SOC measurements enable the identification of patients in need of specific treatment, information or support so as to achieve better targeted healthcare, better subjective health, quality of life, or self-management. Numerous authors conclude that patients' SOC scores should be assessed to inform treatment decisions and interventions (Blom et al., 2010; Boman et al., 1999; Buchi et al., 1998; Ding et al., 2013; Drabe et al., 2015; Forsberg et al., 1996; Klang et al., 1996; Linnen et al., 2011; Matsuura et al., 2003; Myers et al., 2011; Norekval et al., 2010; Spadoti Dantas et al., 2014; Torrati et al., 2010). However, there is also some criticism to use the SOC for this purpose, since authors find its dimensions overlapping with other concepts such as anxiety or diseaserelated depression (Sack et al., 1997), suggesting that the SOC might be a proxy for mental health, well-being, and functionality.

Recommendations on using SOC scores as diagnostic tools are clearly better represented in the literature than recommendations of resulting interventions. With regard to the latter, some authors (e.g., Sales et al., 2014) see a need for more and better studies on the interplay between concepts such as the SOC, quality of life, and treatment outcomes, as a precondition for suggesting effective interventions.

\section{Adapting Treatment Schemes}

Other papers on patients already recommend specific interventions. Implicitly, most recommendations seem to focus on interventions to compensate for a weak SOC, rather than to enhance the SOC in general or one of its dimensions. For 
example, it is widely suggested to adapt treatment schemes for patients with weak SOC scores, mostly in relation to supporting patients' mental health. Interestingly, although most patient-related studies quoted in this paper focus on the SOC, most of the recommended interventions do not explicitly relate to improving or compensating the SOC or one of its dimensions. Across a wide spectrum of conditions, authors recommend rather general psychological or psychotherapeutic interventions to support patients with weak SOC scores. This refers to cancer patients (Forsberg \& Bjorvell, 1996), patients after myocardial infarction (Wrzesniewski \& Wlodarczyk, 2012), patients with rheumatoid arthritis (Buchi et al., 1998), patients after vestibular disease (Tschan et al., 2011), or patients in need of hematopoietic stem cell transplantation (Pillay et al., 2014). Other recommendations for patients with weak SOC scores include specific health promotion attention, such as the recommendation to heart patients to remain physically active (Gustavsson \& Braanholm, 2003; Silarova et al., 2013). Yet another strand of recommendations calls for a "multidimensional" approach that comprises physical, psychological, and social aspects. This perspective is, for example, taken by Schneider et al. (2011) in a study on psoriasis patients, or by Karlsson et al. (1999) in a study on patients undergoing coronary artery bypass grafting. Richardson et al. (2001) conclude that SOC measurements may help to individualize care for diabetes patients, and Kenne et al. (2013) come to similar conclusions for supporting women with breast cancer. Cederfjall et al. (2002) suggest the development of a caring patient-provider relationship for HIV patients with weak SOC scores.

However, there is also a group of papers that relate their recommendations more specifically to salutogenesis, to the SOC in general, or to one of its dimensions. For example, Bergstein et al. (2008) who refer, in addition to the SOC, to the wider salutogenic model, call for interventions that may enhance elements of the SOC in patients with delusional disease, Ahola et al. (2010) formulate similar recommendations for diabetes patients, and Gassmann et al. (2013) for schizophrenic patients. Pusswald et al. (2009) recommend that-in line with Antonovsky's concept of generalized resistance resources-counseling interviews with patients suffering from Parkinson's disease should include analyses of resources available to the patient. Quintard et al. (2013), in a study on the sexual functioning of breast cancer patients, conclude that the patients' perception of available resources - in the sense of manageability of the situationneeds to be enhanced to achieve better outcomes and, also in relation to cancer patients, Gustavsson-Lilius et al. (2012) suggest promoting the SOC to enhance optimism. A paper by Bergman et al. (2012) aims at assessing which of the three dimensions of the SOC is most important for the rehabilitation of patients after first-time myocardial infarction. The authors conclude that comprehensibility is the most important dimension for this group of patients and consequently suggest that this dimension should be supported in healthcare. For patients in ICUs, Akerman et al. (2013) suggest strengthening patients' sense of coherence by photo diaries. And for palliative care, in relation to manageability, a paper by Andershed and Ternestedt (1998) points to the importance of involving patients and relatives in deciding on opportunities for an appropriate death. Glazinski (2007) discusses on how far salutogenesis could become a guiding concept for neurology and psychiatry.

Less common and comparably new is the perception of the SOC being an amenable concept and of patients with weaker SOC being in need of interventions to enhance their SOC. This position is taken in a study by Chenoweth et al. (2008) on patients with Parkinson's disease. They conclude that nurses could contribute to this goal by encouraging their patients to participate in Parkinson's support groups, by teaching them self-management skills and symptom monitoring. Norekval et al. (2010) suggest that patient education might have salutogenic effects. Also, Kvale and Synnes (2013) suggest that the SOC of cancer patients can be enhanced. They explicitly refer to the dimension of manageability that can be supported by adequate pain management strategies, while the dimension of meaningfulness may be enhanced by listening to patients' stories. Li et al. (2015), however, conclude that longitudinal studies on the effects of treatment for a weak SOC are still missing.

Least common in the literature were tests to assess the effectiveness of specific interventions. For example, one study by Johnson et al. (2008) measured and compared effects of quiet reading sessions, human visits, and dog visits, on the SOC of patients undergoing radiation therapy for cancer. While all three types of interventions were experienced as beneficial by the patients, no statistically significant differences could be detected.

\section{Supporting Self-Care and Self-Management}

Papers on patients' ability for self-care or self-management typically interpret a weak SOC as an indication that patients should receive specific support and training to improve selfcare and self-management. For example, in a longitudinal study on smoking cessation in survivors of myocardial infarction, Gerber et al. (2011) conclude that patients with a weak SOC should receive targeted help to quit smoking. Hall-Lord et al. (1999) and Hildingh et al. (2008) call for improved post-hospital support for patients with weak SOC scores. In these papers, a weak SOC at admission is typically interpreted as a risk factor for limited self-care after discharge, so that papers call for a specific support of these patients in discharge planning, such as proactively inviting family members into the planning process, and helping patients to identify resources they can use or rely upon at home. However, one study on chronic patients found that 
those with stronger SOC scores had more hospital admissions while those with weaker SOC scores were more trying to cope for themselves-which probably indicates that a stronger SOC is also related to the ability to delegate caring tasks to healthcare institutions instead of struggling for oneself (compare Kirby et al., 2013).

\section{Supporting Caring Relatives}

Some papers explicitly refer to supportive interventions for caring relatives. In light of Antonovsky's theories, these can be understood as a resource for the patient that can be strengthened by targeted interventions. A specific focus of these papers is on the stress-coping abilities, for example, of family member of patients after stroke (Jaracz et al., 2012) or cancer (Ezer et al., 2006; Schmitt et al., 2008; Tang et al., 2013; Tzuh \& Li, 2008; Yang et al., 2012). However, in a study on family caregivers of Parkinson's disease patients, the authors conclude that the SOC, although found to be relevant to their experience of the caring situation, may be difficult to influence (Caap-Ahlgren \& Dehlin, 2002).

\section{Improving the Impact of Hospital Functioning on Salutogenesis}

Only few studies have an organizational perspective on options to enhance salutogenesis or the SOC, focusing not on additional patient-oriented interventions but on how hospital structures and routine care processes can be used or altered for salutogenic purposes. Concerning salutogenesis as a component in hospital policies, Buscher et al. (2004) note a clear deficit. Based on an analysis of the rehabilitative content of available guidelines for the treatment of patients with mental disorders in Germany, they conclude that none of the guidelines they examined contains explicit referrals to salutogenic aspects of the therapy. With regard to specific recommendations for change, Swenne and Skytt (2013) suggest ways to improve traditional ward rounds so as to allow for more patient participation which the authors consider essential for a good SOC. A paper co-authored by Antonovsky himself (Langius et al., 1992) concludes that the SOC concept should be used to reflect on, and adapt, the way care is provided in hospitals, and Bruscia et al. (2008) call for an improvement in interdisciplinary cooperation to "help cardiac patients perceive life as comprehensible, manageable, and meaningful." With regard to hospital infrastructures, Hasfeldt et al. (2014) emphasize the need to keep ICU noise levels as low as possible, especially to support patients with a weak SOC.

\section{Salutogenic Interventions by Different Healthcare Professions}

Some authors conclude that healthcare professionals need a better general understanding of salutogenesis (e.g., Gilhooly et al., 2007; Helvik et al., 2012). The implications would be that salutogenesis and the SOC should be incorporated into the training curricula of healthcare staff. For this article, we could not assess in how far this is already the case. But we found at least one example, "The handbook of behavioral medicine" (Mostofsky, 2014) that contains several referrals to salutogenesis and its consequences for approaching patients.

Compared to doctors, nurses were more often suggested as potential providers of salutogenic interventions to patients. This probably indicates that nurses use salutogenesis as a concept for further professionalization, and that salutogenic interventions are typically not understood as needing the specific skills of the medical profession. One paper by Menzies (2000) even describes nursing care as a generalized resistance resource in mental healthcare. And several papers outline that salutogenesis or the SOC could be used as guiding concepts for nursing interventions (e.g., Etzel, 2001; Heather, 2013; Mizuno et al., 2009; Onega, 1991; Skarsater et al., 2005). In relation to suicidality, Sjostrom et al., (2012) suggest including the SOC into nursing diagnoses. In a paper by Fok et al. (2005), nurses are recommended to design interventions to enhance the SOC in early phases of hospitalization for critically ill patients. Bergman et al. (2011) found that nurses should support patients after first-time myocardial infarction to identify their risk factors and to support individualized rehabilitation, especially by supporting comprehensibility.

Occupational therapists are another professional group mentioned in the literature. One paper by Schult et al. (2000) recommends they should use SOC measurements for working with chronic pain patients.

\section{Salutogenesis in Relation to Hospital Staff}

All in all, 24 papers with a focus on salutogenesis and hospital staff were identified and analyzed, both with regard to statistical information such as the year of publication and the provenance of the authors, and with relation to content (the use of Antonovsky's concept(s), the groups of staff addressed, and conclusions and consequences).

Papers were published between 1991 and 2014, and over time, there was a clear increase of papers published annually (although not as strong as in the patient-oriented papers): While only five papers had been published in the first decennium of the observation period until 2000 , there were already 
nine papers in the decennium from 2001 to 2010, and in the first 4 years of the third observed decennium from 2011 to 2014 , ten papers had been published. Authors come from all continents with a majority from Europe (14 or 58\%), followed by Asia ( 5 papers or $21 \%$ ), Australia and the USA ( 2 papers or $8 \%$ each), and Africa (1 paper or $4 \%$ ). The single country with most published literature in the field is Sweden (5 articles or $21 \%$ ).

Most articles have a focus on nurses (20\% or $83 \%)$. These typically refer to nurses in specifically demanding caring situations, such as cancer care (Palsson et al., 1994), palliative care (Ablett \& Jones, 2007), or mental healthcare (Berg $\&$ Hallberg, 1999). Three studies are on mixed occupational groups (Hoge \& Bussing, 2004; Nilsson et al., 2013; Rabin et al., 2011) and only one study explicitly addresses doctors (Haoka et al., 2010).

Quite similar to papers on patients, most of the papers on staff are related to the SOC. The majority of these papers are of quantitative character, while a small number either uses the SOC as a theoretical construct to interpret qualitative data (e.g., Ablett \& Jones, 2007; Bringsen et al., 2012) or focuses on the SOC conceptually (Malagon-Aguilera et al., 2012; Reid et al., 2004). The SOC is usually studied in relation to other areas of interest such as perceived work strain (Hoge \& Bussing, 2004; Lewis et al., 1992; Orly et al., 2012; Palsson et al., 1994), perceived reward from work (Haoka et al., 2010), work-family conflict (Takeuchi \& Yamazaki, 2010), self-rated health (Malinauskiene et al., 2011), and, most often, in relation to depression and burn-out in staff (Aries \& Ritter, 1999; Cilliers, 2003; Kikuchi et al., 2014; Nordang et al., 2010; Tselebis et al., 2001). Studies typically conclude that weaker SOC scores are related to lower levels of desired states, such as self-rated health, and to higher levels of undesired states, such as perceived work strain, conflict, or depression and burnout.

Six papers $(25 \%)$ show a more general salutogenic orientation. For example, Bringsen et al. (2012) describe focus group interviews with the aim to identify workplace-related health resources for hospital nurses, or Rabin et al. (2011) "looks at the wide spectrum of stressors found in specialists working in the mental health area... with the salutogenic approach in the background." Nilsson et al. (2013) present a questionnaire with a salutogenic perspective to guide workplace health promotion interventions.

\section{Implications for Occupational Health in Hospitals}

Similar to studies on patients, SOC is so far mainly used to identify staff members at higher risk of developing problematic conditions, such as burnout, and thus being in need of extra support. A weak SOC seems to be widely used as an indicator for the vulnerability of staff to work-specific stressors, while strong SOC typically is understood as a buffer against job strain (e.g., Malinauskiene et al., 2009). But there are also some more resource-oriented papers such as the one by Bringsen et al. (2011) that has a more general salutogenic orientation and uses this lens to identify work-specific resources for staff, such as flow situations.

While some papers conclude by describing the study results (e.g., Aries \& Ritter, 1999; Hoge \& Bussing, 2004; Lewis et al., 1994; Malagon-Aguilera et al., 2012; Malinauskiene et al., 2009; Nordang et al., 2010), others suggest interventions for improvements. Papers with a focus on the SOC often (but not exclusively) frame their conclusions more in the direction of risk orientation and risk reduction, while papers with a more general salutogenic orientation focus more on resource-strengthening. However, both perspectives come to rather similar recommendations with regard to suggestions for interventions. On the one hand, the recommended interventions refer to improvements of potentially strenuous work conditions such as high work load (e.g., Rabin et al., 2011) or generally adverse working conditions (Malinauskiene et al., 2011). On the other hand, support of individual staff members is recommended in the form of supervision (Berg \& Hallberg, 1999; Palsson et al., 1994), mentoring (Cilliers \& Terblanche, 2014), mindfulness meditation (Foureur et al., 2013), training and peer support (Michael \& Jenkins, 2001), or targeted support for staff with burnout symptoms (Tselebis et al., 2001). Some authors also recommend a combination of organization- and individualrelated interventions (e.g., Cilliers, 2003; Reid et al., 2004) as both may contribute to a better use of coping resources (Lewis et al., 1994). Bringsen et al. (2012), on the basis of a qualitative study, emphasize that different types of hospital staff may need different types of supportive interventions.

Less common and more recent are studies calling for actual improvements of a weak SOC in staff (e.g., Kikuchi et al., 2014). One study by Orly et al. (2012) describes the measurement of SOC scales in nurses' pre and post cognitive-behavioral interventions, with significant improvements post intervention. In a similar study on the effects of mindfulness-based meditation, Foureur et al. (2013) also report positive effects, while Berg and Hallberg (1999) could not detect any significant improvements in SOC scores following supervision.

Summing up, while there seems to be increasingly strong evidence for the interrelations between SOC and the (mental) health of hospital staff, the literature is less clear with regard to the type of interventions that should be used either to compensate, or to improve a weak SOC. 


\section{Salutogenesis and Health-Promoting Hospitals (HPHs)}

Since salutogenesis is referred to as one of the theoretical backgrounds of health promotion, it is worthwhile to explore in how far salutogenesis has so far been taken up in HPH, an international network initiated by WHO-Euro that aims at supporting the reorientation of hospitals toward health promotion (Milz \& Vang, 1989; Pelikan et al., 2001; WHO, 1991, 1997).

HPHs are based on a WHO initiative in relation to the settings approach in health promotion. They still seem to be exotic birds in the hospital world: While the ten nation states with most hospitals per country alone have more than 150,000 hospitals (according to Maps of the World), the roughly 1000 member organizations of the International HPH network make far less than 1 per mille of the hospitals on the planet.

Following the Ottawa Charter's (WHO, 1986) demand to "reorient health services," WHO had started consultation on how to bring this approach into practice in 1988, focusing on hospitals as the core organizations in modern healthcare systems. Subsequently, a model project in Vienna (1989-1997), a European pilot hospital project (1993-1997), and an international network (starting in 1990) were initiated by WHOEuro. Since 2008, HPH is an international nonprofit association, operates in all continents and is organized in about 40 national and regional networks, coordinated by an international supra-network with a general assembly and elected governance board, and is supported by specific thematic task forces and two WHO collaborating centers (Dietscher, 2012, 2013; Pelikan et al., 2011).

Content-wise, HPHs are oriented at the Ottawa Charter's definition of health promotion which is "the process to increase control over, and to improve, one's health" (WHO, 1986). Defined target or stakeholder groups of HPH are not only patients (and their significant others) but also staff and community members (people in neighborhoods and catchment areas). From the beginning, HPH was dedicated to principles of organizational development and quality improvement, understanding health promotion not (only) as additional (consultative) services but rather as the way health promotion is addressed and integrated into the core processes of healthcare organizations, as outlined in two policy papers, the Budapest Declaration on HPH (WHO, 1991) and the Vienna Recommendations on HPH (WHO, 1997). This background was the basis for formulating $18 \mathrm{HPH}$ core strategies-six main HPH intervention areas, for each of the three defined target groups. These areas or principles are (1) to support healthy living in the organization (maintaining and strengthening healthy aspects while in care or, for staff, during working life), (2) to improve co-production, (3) to develop the physical and social healthcare setting into a health-promoting environment, (4) to empower for disease management, (5) to empower for healthy lifestyles, and (6) to contribute to health-promoting community development (Pelikan et al., 2005) (Table 37.6). To support linking HPH to quality management, 5 standards (Gröne, 2006) and 7

Table 37.6 Eighteen HPH core strategies (Pelikan et al., 2005, modified). With permission of @ World Health Organization 2005

\begin{tabular}{|c|c|c|c|}
\hline Target group strategy & Patients & Staff & Community \\
\hline \multirow[t]{2}{*}{$\begin{array}{l}\text { Empowerment of stakeholders for } \\
\text { health-promoting self- } \\
\text { reproduction/self-management }\end{array}$} & $\begin{array}{l}\text { Developing health-promoting } \\
\text { living conditions for patients in } \\
\text { the hospital }\end{array}$ & $\begin{array}{l}\text { Developing health- } \\
\text { promoting work life for } \\
\text { staff }\end{array}$ & $\begin{array}{l}\text { Developing health promoting access } \\
\text { to the hospital for citizens }\end{array}$ \\
\hline & PAT-1 & STA-1 & COM-1 \\
\hline \multirow[t]{2}{*}{$\begin{array}{l}\text { Empowerment of stakeholders for } \\
\text { health-promoting coproduction }\end{array}$} & $\begin{array}{l}\text { Encouraging patients' } \\
\text { participation, cooperation, and } \\
\text { co-production in treatment and } \\
\text { care }\end{array}$ & $\begin{array}{l}\text { Encouraging health- } \\
\text { promoting work } \\
\text { processes }\end{array}$ & $\begin{array}{l}\text { Developing health-promoting } \\
\text { cooperation's with services in the } \\
\text { region }\end{array}$ \\
\hline & PAT-2 & STA-2 & COM-2 \\
\hline \multirow[t]{2}{*}{$\begin{array}{l}\text { Health-promoting \& empowering } \\
\text { hospital setting for stakeholders }\end{array}$} & $\begin{array}{l}\text { Developing a health-promoting } \\
\text { hospital setting for patients }\end{array}$ & $\begin{array}{l}\text { Developing a health- } \\
\text { promoting workplace } \\
\text { setting for staff }\end{array}$ & $\begin{array}{l}\text { Developing the hospital as a health- } \\
\text { promoting environment for the } \\
\text { community }\end{array}$ \\
\hline & PAT-3 & STA-3 & COM-3 \\
\hline \multirow[t]{2}{*}{$\begin{array}{l}\text { Empowering illness management } \\
\text { (patient education) for } \\
\text { stakeholders }\end{array}$} & $\begin{array}{l}\text { Encouraging patients' health- } \\
\text { promoting self-management of } \\
\text { specific diseases }\end{array}$ & $\begin{array}{l}\text { Encouraging staff's } \\
\text { health-promoting illness } \\
\text { management }\end{array}$ & $\begin{array}{l}\text { Participate in alliances to encourage } \\
\text { citizens for a health-promoting } \\
\text { self-management of specific diseases }\end{array}$ \\
\hline & PAT-4 & STA-4 & COM-4 \\
\hline \multirow[t]{2}{*}{$\begin{array}{l}\text { Empowering lifestyle development } \\
\text { (health education) for stakeholders }\end{array}$} & $\begin{array}{l}\text { Encouraging patients to lead a } \\
\text { health-promoting lifestyle }\end{array}$ & $\begin{array}{l}\text { Encouraging staff to lead } \\
\text { a health-promoting } \\
\text { lifestyle }\end{array}$ & $\begin{array}{l}\text { Participate in alliances to encourage } \\
\text { citizens to lead a health-promoting } \\
\text { lifestyle }\end{array}$ \\
\hline & PAT-5 & STA-5 & COM-5 \\
\hline \multirow[t]{2}{*}{$\begin{array}{l}\text { Participation in health-promoting } \\
\text { \& empowering community } \\
\text { development for stakeholders }\end{array}$} & $\begin{array}{l}\text { Developing health-promoting } \\
\text { living conditions for patients after } \\
\text { leaving the hospital }\end{array}$ & $\begin{array}{l}\text { Developing a health- } \\
\text { promoting community } \\
\text { setting for staff }\end{array}$ & $\begin{array}{l}\text { Participate in alliances to develop } \\
\text { health-promoting community settings }\end{array}$ \\
\hline & PAT-6 & STA-6 & COM-6 \\
\hline
\end{tabular}


implementation strategies (Pelikan, 2007) were also developed.

Summing up, a health-promoting hospital is actively attempting to integrate health promotion criteria into its decision premises and processes, and, consequently, taking comprehensive and continuous action to promote the health of its patients, staff, and the population in the community it serves (Pelikan et al., 2001). A bibliography on published literature in the field of HPH was published by Dietscher et al. (2014).

\section{Conceptual and Practical Links Between HPH and Salutogenesis}

The above-mentioned official HPH documents do not contain any explicit referrals to salutogenesis. Still, HPH has an implicit salutogenic orientation, focusing on a comprehensive concept of health and on strengthening the resources for health (e.g., by empowerment), as well as on reducing risks for diseases for a wide set of target groups, no matter where they are on the health-disease continuum.

However, while Antonovsky's general concept and also his specific salutogenic model are typically understood as a psychological concept, or rather as a theory on individual coping with challenges leading to tension and possibly stress, $\mathrm{HPH}$ - so as other setting-oriented health promotion strategies-is more oriented toward changing organizational characteristics that are either challenging or support coping for individuals and groups. HPH aims at using hospitals as settings in which both situative and individual health determinants can be addressed by individual as well as organizational interventions. In this respect, both concepts can be interpreted as complementary: salutogenesis provides a concept that can be pursued by the intervention strategies of HPH. Furthermore, the SOC concept and questionnaires might be interesting tools for developing HPH. Measurement tools developed by HPH itself-such as the self-assessment tool for the five HPH standards (Gröne, 2006) - assess whether health-promoting structures (and partly also interventions) are in place. The SOC could-at least in principle-be used to design specific health promotion interventions and to measure their effectiveness. Although the scientific debate on whether the SOC is ultimately shaped during childhood and adolescence or whether it can be altered in later life is ongoing, empirical data quoted in this chapter seem to support the hypothesis that the SOC of an individual can be improved or decreased also in adult life besides being taken into account by the hospital. Therefore, it seems plausible to suggest that SOC measurements prepost targeted interventions may also produce data on the effectiveness of health promotion interventions.

As far as we could detect from the abstract books of HPH conferences that were published over the last 10 years, 33 papers-less than $1 \%$ of all abstract published during the observation period-had an explicit referral to salutogenesis. The number of related papers submitted annually seems largely related to the respective Calls for Papers (e.g., as the program of the HPH conference in 2011 in Turku, Finland, had a focus on salutogenesis, considerably more related papers than on average were submitted that year). Target groups and applications of the salutogenesis approach in HPH papers were quite similar as in the literature search outlined in this article. One difference, however, was that HPH papers also included papers on salutogenic community interventions by hospitals, probably because community citizens are one of the three explicit target groups of HPH.

Apart from the conference papers, quite a number of international HPH activities can be clearly related to one or more dimensions of the SOC. For example, HPH task forces that address topics such as health-promoting psychiatric health care, health promotion for children and adolescents in hospitals, or migrant-friendly and culturally competent hospitals, have been systematically calling for better comprehensibility and manageability, especially for vulnerable groups by adapting healthcare services to the needs of these groups.

\section{Discussion and Conclusions}

In this chapter, we contrast our theoretical considerations on the role salutogenesis could play in hospitals with the topics actually covered in the available reviewed literature. We will then discuss the limitations of our approach and suggest some resulting needs for further research.

\section{A General Salutogenic Orientation and the Salutogenic Model}

The literature in the hospital field that relates to a general salutogenic orientation of the hospital setting is scarce, as is the hospital-related literature referring to Antonovsky's complex salutogenic model. The few examples that exist remain rather normative and vague when it comes to concrete recommendations for resulting interventions to develop hospital's structures, cultures, and processes. While there exist some literature and research concerning the role of salutogenesis for the role and work of nurses, salutogenesis for and by medical doctors still is a potential to be discovered and implemented.

Concerning the general salutogenic model, in light of the available literature, especially three desiderata remain that provide ample room for future research and practice. First, following Antonovsky, a salutogenic approach means a consequent orientation at resources (not just risks). But a practical and hospital-specific (and partly even diagnosis-specific) concept and typecast of the health-relevant general and spe- 
cific resistance resources of patients (and staff), as well as of interventions to activate them, is still lacking. Next to personrelated resources such as physical, mental, and socioeconomic resources, as well as personal lifestyles, this typecast should also comprise resources related to the functioning of the hospital itself and to the way hospital core processes are run, as suggested by some of the papers quoted in this chapter. These hospital-internal resources would include caring styles, options for patient participation in treatment decisions and care, the support of patient health literacy (compare, e.g., Brach et al., 2012), or the kind of support available at discharge, or when progressing from hospitals to other providers of care. Second, a set of applicable interventions that can effectively activate these resources, as well as evidence on their effectiveness, would be required. Third, it would be necessary to understand salutogenesis as a feature of organizational quality, not only as characteristic of interaction between individuals, and thus to develop and evaluate models for developing salutogenic organizational structures and capacities for supporting the salutogenesis of the people affected by these organizations.

Furthermore, with regard to Antonovsky's comprehensive salutogenic model, practically none of the papers refers to the model in its totality. If at all, papers used concepts such as coping with stress, or generalized resistance resources. Against this background, especially a more thorough reflection of the stressors hospitals themselves produce by their way of functioning, and measures to avoid them, would be desirable.

\section{The Sense of Coherence}

The vast majority of the literature retrieved for this article somehow relates to the SOC. However, the SOC is, rather paradoxically, widely used with a risk perspective rather than a resource perspective. By use of the diverse available SOC questionnaires, the SOC is typically treated as a diagnostic concept. Mainly, a weak SOC is understood as a risk factor for numerous conditions. And most studies treat the SOC as an absolute or fixed personality trait but do not reflect on how hospital structures and processes themselves can impact on the SOC and its dimensions of comprehensibility, manageability, and meaningfulness.

\section{Which Intervention Approaches Are Suggested for Whom?}

In line with the outlined research perspectives, the salutogenic interventions suggested by the authors of the retrieved papers are, in line with medical interventionist thinking, mainly person-oriented, and here again, mostly relating to hospital patients, mainly with rather severe diseases. Few also address hospital staff, but rarely medical doctors and hardly any the people in the hospitals' communities. Most papers refer to compensating for patients' weak SOC with specific supportive interventions. Only a minority of papers has an organizational approach, considering how the hospital functioning as such could reduce stress and improve comprehensibility, manageability, and meaningfulness for patients, staff, and visitors alike.

Furthermore, in contrast to Antonovsky's demand to "encompass all persons, wherever they are on the continuum" (Antonovsky, 1996, p. 14), the available research on salutogenesis and hospitals has a clear focus on the disease side of the continuum, widely treating a weak SOC as a risk for self-perceived health, self-management, and quality of life.

\section{Needs for Further Research}

The literature reviewed for this article had no homogenous understanding of salutogenesis or the SOC. There seems to be good evidence for positive interrelations between salutogenesis, especially the sense of coherence, and subjective health, quality of life, and self-care ability. There is also evidence for positive interrelations between the SOC and mental health. However, it remains unclear and widely depending on the study perspective whether the SOC is viewed as a predictor, mediator (Tang et al., 2013), or moderator of desired outcomes, or even as an outcome itself. For example, while some authors see the SOC as a predictor of symptom severity, others interpret symptom severity and specific personality traits as impacting on the SOC. And in the emerging field of research on the SOC being an amenable concept, SOC levels are viewed as an outcome of interventions. Thus, it seems that more conceptual clarity on the role the SOC actually plays in relation to health still needs to be achieved and more complex designs to research this are needed. Furthermore, research is needed on the question why there is clear evidence for interlinks between the SOC and subjective health but hardly any proof for the SOC's impact on dimensions of health that do not appear directly related to subjective well-being or personal self-management.

When it comes to researching salutogenic interventions, we would argue that more emphasis should be given to researching the impact of hospital functioning and organizational interventions on salutogenesis or the SOC, and for person-oriented interventions, that more systematic research on the effectiveness of these interventions would be needed.

Finally, we suggest further research on the potential applicability of SOC measurements to assess the outcomes of health promotion interventions, on the level of both organizations and individuals, as well as concepts and research on implications for healthcare financing and healthcare curricula. 


\section{Limitations}

The empirical part of this chapter is widely based on a systematic literature search and on a content analysis of abstracts of published research that contain explicit referrals to salutogenesis in relation to hospitals. Because of the inclusion and exclusion criteria that were decided upon, some papers that might be relevant for the context of this paper may have been overlooked if they do not contain explicit referrals to Antonovsky's concepts.

Furthermore, because of resource constraints, our analysis of the reviewed articles was limited to the abstracts of the retrieved and included papers. Since our main aim was to develop an overview on the topics that are already covered by hospital-related research in relation to salutogenesis, we consider this methodological decision justifiable. Still, more details could of course have been gained by a thorough analysis of the full papers.

As far as health promotion in hospitals is concerned, the international Network of Health-Promoting Hospitals and Health Services represents only a scarce but systematic and explicitly declared part of actual health promotion in hospitals. There is much more health promotion going on in hospitals, also without using the label, which also will have its links to salutogenesis.

\section{References}

Ablett, J. R., \& Jones, R. S. (2007). Resilience and Well-being in palliative care staff: A qualitative study of hospice nurses' experience of work. Psychooncology, 16(8), 733-740.

Ahola, A. J., Mikkila, V., Saraheimo, M., Waden, J., Makimattila, S., Forsblom, C., et al. (2012). Sense of coherence, food selection and leisure time physical activity in type 1 diabetes. Scandinavian Journal of Public Health, 40(7), 621-628.

Ahola, A. J., Saraheimo, M., Forsblom, C., Hietala, K., \& Groop, P. H. (2010). The cross-sectional associations between sense of coherence and diabetic microvascular complications, glycaemic control, and patients' conceptions of type 1 diabetes. Health and Quality of Life Outcomes, 8, 142. https://doi. org/10.1186/1477-7525-8-142

Akerman, E., Ersson, A., Fridlund, B., \& Samuelson, K. (2013). Preferred content and usefulness of a photodiary as described by ICU-patients-A mixed method analysis. Australian Critical Care, 26(1), 29-35.

Andershed, B., \& Ternestedt, B. M. (1998). Involvement of relatives in the care of the dying in different care cultures: Involvement in the dark or in the light? Cancer Nursing, 21(2), 106-116.

Antonovsky, A. (1996). The salutogenic model as a theory to guide health promotion. Health Promotion International, 11(1), 11-18.

Apers, S., Luyckx, K., Rassart, J., Goossens, E., Budts, W., \& Moons, P. (2013). Sense of coherence is a predictor of perceived health in adolescents with congenital heart disease: A cross-lagged prospective study. International Journal of Nursing Studies, 50(6), 776-785.

Aries, M., \& Ritter, I. Z. (1999). Nurses with and without burnout: A comparison. Results of a quantitative longitudinal study and a qualitative depth study. Pflege, 12(2), 83-88.
Aust, B., \& Ducki, A. (2004). Comprehensive health promotion interventions at the workplace: Experiences with health circles in Germany. Journal of Occupational Health Psychology, 9(3), 258270. https://doi.org/10.1037/1076-8998.9.3.258

Barthelsson, C., Nordstrom, G., \& Norberg, A. (2011). Sense of coherence and other predictors of pain and health following laparoscopic cholecystectomy. Scandinavian Journal of Caring Sciences, 25(1), 143-150.

Beauchemin, K. M., \& Hays, P. (1998). Dying in the dark: Sunshine, gender and outcomes in myocardial infarction. Journal of the Royal Society of Medicine, 91(7), 352-354.

Benyamini, Y., Roziner, I., Goldbourt, U., Drory, Y., \& Gerber, Y (2013). Depression and anxiety following myocardial infarction and their inverse associations with future health behaviors and quality of life. Annals of Behavioral Medicine, 46(3), 310-321.

Berg, A., \& Hallberg, I. R. (1999). Effects of systematic clinical supervision on psychiatric nurses' sense of coherence, creativity, workrelated strain, job satisfaction and view of the effects from clinical supervision: A pre-post test design. Journal of Psychiatric and Mental Health Nursing, 6(5), 371-381.

Berg, J. E., \& Kononova, N. (2009). Sense of coherence in patients treated for depression with ECT. International Journal of P sychiatry in Medicine, 39(1), 101-112.

Berger, H. (2003). Health promotion-A new approach in psychiatry. Psychiatrische Praxis, 30(Suppl 1), 14-20.

Bergman, E., Arestedt, K., Fridlund, B., Karlsson, J. E., \& Malm, D. (2012). The impact of comprehensibility and sense of coherence in the recovery of patients with myocardial infarction: A long-term follow-up study. European Journal of Cardiovascular Nursing, 11(3), 276-283.

Bergman, E., Malm, D., Bertero, C., \& Karlsson, J. E. (2011). Does one's sense of coherence change after an acute myocardial infarction? A two-year longitudinal study in Sweden. Nursing and Health Sciences, 13(2), 156-163.

Bergman, E., Malm, D., Karlsson, J. E., \& Bertero, C. (2009). Longitudinal study of patients after myocardial infarction: Sense of coherence, quality of life, and symptoms. Heart and Lung, 38(2), 129-140.

Bergstein, M., Weizman, A., \& Solomon, Z. (2008). Sense of coherence among delusional patients: Prediction of remission and risk of relapse. Comprehensive Psychiatry, 49(3), 288-296.

Bergsten, B. A., Hjelte, L., \& Hochwalder, J. (2011). Mental health and sense of coherence among Swedish adults with cystic fibrosis. Scandinavian Journal of Caring Sciences, 25(2), 365-372.

Blom, E. H., Larsson, J. O., Serlachius, E., \& Ingvar, M. (2010). The differentiation between depressive and anxious adolescent females and controls by behavioural self-rating scales. Journal of Affective Disorders, 122(3), 232-240.

Boman, L., Bjorvell, H., Langius, A., \& Cedermark, B. (1999). Two models of care as evaluated by a group of women operated on for breast cancer with regard to their perceived well-being. European Journal Cancer Care, 8(2), 87-96.

Boscaglia, N., \& Clarke, D. M. (2007). Sense of coherence as a protective factor for demoralisation in women with a recent diagnosis of gynaecological cancer. Psychooncology, 16(3), 189-195.

Brach, C., Keller, D., Hernandez, L. M., et al. (2012). Ten attributes of health literate health care organizations. Institute of Medicine.

Bringsen, A., Andersson, H. I., Ejlertsson, G., \& Troein, M. (2012). Exploring workplace related health resources from a salutogenic perspective. Results from a focus group study among healthcare workers in Sweden. Work, 42(3), 403-414.

Bringsen, A., Ejlertsson, G., \& Andersson, I. H. (2011). Flow situations during everyday practice in a medical hospital ward. Results from a study based on experience sampling method. BMC Nursing, 10, 3 . https://doi.org/10.1186/1472-6955-10-3 
Bruscia, K., Shultis, C., Dennery, K., \& Dileo, C. (2008). Predictors of quality of life in hospitalized cardiac patients. Journal of Health Psychology, 13(8), 982-987.

Buchi, S., Sensky, T., Allard, S., Stoll, T., Schnyder, U., Klaghofer, R., et al. (1998). Sense of coherence-A protective factor for depression in rheumatoid arthritis. Journal of Rheumatology, 25(5), 869-875.

Buscher, C., Watzke, B., Koch, U., \& Schulz, H. (2004). The development of guidelines for the treatment of patients with mental disorders under particular consideration of rehabilitative aspects. Psychosocial Medicine, 1, Doc05.

Caap-Ahlgren, M., \& Dehlin, O. (2002). Factors of importance to the caregiver burden experienced by family caregivers of Parkinson's disease patients. Aging Clinical and Experimental Research, 14(5), 371-377.

Cederfjall, C., Langius-Eklof, A., Lidman, K., \& Wredling, R. (2001). Gender differences in perceived health-related quality of life among patients with HIV infection. AIDS Patient Care and STDs, 15(1), 31-39.

Cederfjall, C., Langius-Eklof, A., Lidman, K., \& Wredling, R. (2002). Self-reported adherence to antiretroviral treatment and degree of sense of coherence in a group of HIV-infected patients. AIDS Patient Care and STDs, 16(12), 609-616.

Cederlund, R. I., Ramel, E., Rosberg, H. E., \& Dahlin, L. B. (2010). Outcome and clinical changes in patients 3, 6, 12 months after a severe or major hand injury-Can sense of coherence be an indicator for rehabilitation focus? BMC Musculoskeletal Disorders, 11, 286. https://doi.org/10.1186/1471-2474-11-286

Chenoweth, L., Gallagher, R., Sheriff, J. N., Donoghue, J., \& SteinParbury, J. (2008). Factors supporting self-management in Parkinson's disease: Implications for nursing practice. International Journal of Older People Nursing, 3(3), 187-193.

Cilliers, F. (2003). Burnout and salutogenic functioning of nurses. Curationis, 26(1), 62-74.

Cilliers, F., \& Terblanche, L. (2014). The role of spirituality in coping with the demands of the hospital culture amongst fourthyear nursing students. International Review of Psychiatry, 26(3), 279-288.

Coulter, A., \& Ellins, J. (2007). Effectiveness of strategies for informing, educating, and involving patients. BMJ, 335(7609), 24-27.

Dietscher, C. (2012). Interorganizational networks in the setting approach of health promotion-The case of the international network of health promoting hospitals and health services (HPH). University of Vienna.

Dietscher, C. (2013). How can the functioning and effectiveness in the settings approach of health promotion be understood, achieved and researched? Health Promotion International. https://doi. org/10.1093/heapro/dat067

Dietscher, C., Pelikan, J. M., \& Schmied, H. (2014). Health promoting hospitals. In D. McQueen (Ed.), Oxford bibliographies in public health. Oxford University Press.

Dietscher, C., \& Pelikan, J. M. (2016). Soziologie der Krankheitsprävention. In M. Richter \& K. Hurrelmann (Eds.), Soziologie von Gesundheit und Krankheit (pp. 417-434). Springer VS.

Dilani, A., \& Armstrong, K. (2008). The "salutogenic" approachDesigning a health-promoting hospital environment. World Hospitals and Health Services, 44(3), 32-35.

Ding, Y., Hu, Y., \& Hallberg, I. R. (2013). Health-related quality of life and associated factors in Chinese women with cervical cancer: A 9-month follow-up. Cancer Nursing, 36(4), E18-E26.

Drabe, N., Klaghofer, R., Weidt, S., Zwahlen, D., Buchi, S., \& Jenewein, J. (2015). Mutual associations between patients' and partners' depression and quality of life with respect to relationship quality, physical complaints, and sense of coherence in couples coping with cancer. Psychooncology, 24(4), 442-450. https://doi.org/10.1002/ pon. 3662
Drory, Y., Kravetz, S., \& Florian, V. (1999). Psychosocial adjustment in patients after a first acute myocardial infarction: The contribution of salutogenic and pathogenic variables. Israel study group on first acute myocardial infarction. Archives of Physical Medicine and Rehabilitation, 80(7), 811-818.

Dubs, L. (1999). Everything was done-Patient still not satisfied: Introduction to evidence-based surgery. Swiss Surgery, 5(4), $160-166$.

Eklund, M., Hansson, L., \& Bengtsson-Tops, A. (2004). The influence of temperament and character on functioning and aspects of psychological health among people with schizophrenia. European Psychiatry, 19(1), 34-41.

Etzel, B. S. (2001). Care at the Tumor Biology Center Freiburg-On the way. Onkologie, 24(Suppl 1), 80-85.

Eurofound. (2012). Fifth European working conditions survey. Publications Office of the European Union.

Ezer, H., Chachamovich, J. R., Saad, F., Aprikian, A., \& Souhami, L. (2012). Psychosocial adjustment of men during the first year of prostate cancer. Cancer Nursing, 35(2), 141-147.

Ezer, H., Ricard, N., Bouchard, L., Souhami, L., Saad, F., Aprikian, A., et al. (2006). Adaptation of wives to prostate cancer following diagnosis and 3 months after treatment: A test of family adaptation theory. International Journal of Nursing Studies, 43(7), 827-838.

Fink, N. S., Urech, C., Cavelti, M., \& Alder, J. (2012). Relaxation during pregnancy: What are the benefits for mother, fetus, and the newborn? A systematic review of the literature. The Journal of Perinatal \& Neonatal Nursing, 26(4), 296-306.

Fok, S. K., Chair, S. Y., \& Lopez, V. (2005). Sense of coherence, coping and quality of life following a critical illness. Journal of Advanced Nursing, 49(2), 173-181.

Forsberg, C., \& Bjorvell, H. (1996). Living with cancer: Perceptions of Well-being. Scandinavian Journal of Caring Sciences, 10(2), 109-115.

Forsberg, C., Bjorvell, H., \& Cedermark, B. (1996). Well-being and its relation to coping ability in patients with colorectal and gastric cancer before and after surgery. Scandinavian Journal of Caring Sciences, 10(1), 35-44.

Foureur, M., Besley, K., Burton, G., Yu, N., \& Crisp, J. (2013). Enhancing the resilience of nurses and midwives: Pilot of a mindfulness-based program for increased health, sense of coherence and decreased depression, anxiety and stress. Contemporary Nurse, 45(1), 114-125.

Gassmann, W., Christ, O., Lampert, J., \& Berger, H. (2013). The influence of Antonovsky's sense of coherence (SOC) and psychoeducational family intervention (PEFI) on schizophrenic outpatients' perceived quality of life: A longitudinal field study. BMC Psychiatry, 13, 10. https://doi.org/10.1186/1471-244X-13-10

Gerber, Y., Benyamini, Y., Goldbourt, U., \& Drory, Y. (2009). Prognostic importance and long-term determinants of self-rated health after initial acute myocardial infarction. Medical Care, 47(3), 342-349.

Gerber, Y., Koren-Morag, N., Myers, V., Benyamini, Y., Goldbourt, U., \& Drory, Y. (2011). Long-term predictors of smoking cessation in a cohort of myocardial infarction survivors: A longitudinal study. European Journal of Cardiovascular Prevention \& Rehabilitation, 18(3), 533-541.

Gigerenzer, G. (2014). Risk savvy. How to make good decision. Viking.

Gigerenzer, G., \& Gray, J. A. M. (2011). Launching the century of the patient. In G. Gigerenzer \& J. A. M. Gray (Eds.), Better doctors, better patients, better decisions: Envisioning health care 2020 (pp. 3-28). MIT Press.

Gilhooly, M., Hanlon, P., Cullen, B., Macdonald, S., \& Whyte, B. (2007). Successful ageing in an area of deprivation: Part 2-A quantitative exploration of the role of personality and beliefs in good health in old age. Public Health, 121(11), 814-821. 
Glazinski, R. (2007). Social-medical significance of the concept of salutogenesis in neurology and psychiatry. Gesundheitswesen, 69(3), 134-136.

Gröne, O. (2006). Implementing health promotion in hospitals: Manual and self-assessment forms. WHO Regional Office for Europe.

Gudmundsdottir, E., Schirren, M., \& Boman, K. K. (2011). Psychological resilience and long-term distress in Swedish and Icelandic parents' adjustment to childhood cancer. Acta Oncologica, 50(3), 373-380.

Gustavsson, A., \& Braanholm, I. B. (2003). Experienced health, life satisfaction, sense of coherence, and coping resources in individuals living with heart failure. Scandinavian Journal of Occupational Therapy, 10(3), 138-143.

Gustavsson-Lilius, M., Julkunen, J., Keskivaara, P., Lipsanen, J., \& Hietanen, P. (2012). Predictors of distress in cancer patients and their partners: The role of optimism in the sense of coherence construct. Psychology and Health, 27(2), 178-195.

Hall-Lord, M. L., Larsson, G., \& Steen, B. (1999). Chronic pain and distress in older people: A cluster analysis. International Journal of Nursing Practice, 5(2), 78-85.

Haoka, T., Sasahara, S., Tomotsune, Y., Yoshino, S., Maeno, T., \& Matsuzaki, I. (2010). The effect of stress-related factors on mental health status among resident doctors in Japan. Medical Education, 44(8), 826-834.

Hasfeldt, D., Maindal, H. T., Toft, P., \& Birkelund, R. (2014). Patients' perception of noise in the operating room-a descriptive and analytic cross-sectional study. Journal of Perianesthesia Nursing, 29(5), 410-417.

Heather, H. (2013). An asset-based approach to creating health. Nursing Times, 109(4), 19-21.

Helvik, A. S., Engedal, K., Bjorklof, G. H., \& Selbaek, G. (2012). Factors associated with perceived health in elderly medical inpatients: A particular focus on personal coping recourses. Aging \& Mental Health, 16(6), 795-803.

Henoch, I., Bergman, B., Gustafsson, M., Gaston-Johansson, F., \& Danielson, E. (2007). The impact of symptoms, coping capacity, and social support on quality of life experience over time in patients with lung cancer. Journal of Pain and Symptom Management, 34(4), 370-379.

Hildingh, C., Fridlund, B., \& Baigi, A. (2008). Sense of coherence and experiences of social support and mastery in the early discharge period after an acute cardiac event. Journal of Clinical Nursing, 17(10), 1303-1311.

Hoge, T., \& Bussing, A. (2004). The impact of sense of coherence and negative affectivity on the work stressor-Strain relationship. Journal of Occupational Health Psychology, 9(3), 195-205.

Hyphantis, T., Palieraki, K., Voulgari, P. V., Tsifetaki, N., \& Drosos, A. A. (2011). Coping with health-stressors and defence styles associated with health-related quality of life in patients with systemic lupus erythematosus. Lupus, 20(9), 893-903.

Hyphantis, T. N., Tsifetaki, N., Pappa, C., Voulgari, P. V., Siafaka, V., Bai, M., et al. (2007). Clinical features and personality traits associated with psychological distress in systemic sclerosis patients. Journal of Psychosomatic Research, 62(1), 47-56.

Jaracz, K., Grabowska-Fudala, B., \& Kozubski, W. (2012). Caregiver burden after stroke: Towards a structural model. Neurologia $i$ Neurochirurgia Polska, 46(3), 224-232.

Johnson, R. A., Meadows, R. L., Haubner, J. S., \& Sevedge, K. (2008). Animal-assisted activity among patients with cancer: Effects on mood, fatigue, self-perceived health, and sense of coherence. Oncology Nursing Forum, 35(2), 225-232.

Karlsson, I., Berglin, E., Pettersson, G., \& Larsson, P. A. (1999) Predictors of chest pain after coronary artery bypass grafting. Scandinavian Cardiovascular Journal, 33(5), 289-294.

Kenne, S. E., Browall, M., \& Gaston-Johansson, F. (2013). Symptom burden clusters: A challenge for targeted symptom management.
A longitudinal study examining symptom burden clusters in breast cancer. Journal of Pain and Symptom Management, 47(4), 731-741.

Khanjari, S., Oskouie, F., \& Langius-Eklof, A. (2012). Lower sense of coherence, negative religious coping, and disease severity as indicators of a decrease in quality of life in Iranian family caregivers of relatives with breast cancer during the first 6 months after diagnosis. Cancer Nursing, 35(2), 148-156.

Kikuchi, Y., Nakaya, M., Ikeda, M., Okuzumi, S., Takeda, M., \& Nishi, M. (2014). Relationship between depressive state, job stress, and sense of coherence among female nurses. Indian Journal of Occupational and Environmental Medicine, 18(1), 32-35.

Kirby, S. E., Dennis, S. M., Bazeley, P., \& Harris, M. F. (2013). Activating patients with chronic disease for self-management: Comparison of self-managing patients with those managing by frequent readmissions to hospital. Australian Journal of Primary Health, 19(3), 198-206.

Klang, B., Bjorvell, H., \& Cronqvist, A. (1996). Patients with chronic renal failure and their ability to cope. Scandinavian Journal of Caring Sciences, 10(2), 89-95.

Kusnekov, A. W., \& Anisman, H. (Eds.). (2013). The Wiley-Blackwell handbook of psychoneuroimmunology. Wiley Blackwell.

Kvale, K., \& Synnes, O. (2013). Understanding cancer patients' reflections on good nursing care in light of Antonovsky's theory. European Journal of Oncology Nursing, 17(6), 814-819.

Langius, A., Bjorvell, H., \& Antonovsky, A. (1992). The sense of coherence concept and its relation to personality traits in Swedish samples. Scandinavian Journal of Caring Sciences, 6(3), 165-171.

Langius, A., Bjorvell, H., \& Lind, M. G. (1994). Functional status and coping in patients with oral and pharyngeal cancer before and after surgery. Head and Neck, 16(6), 559-568.

Langius, A., \& Lind, M. G. (1995). Well-being and coping in oral and pharyngeal cancer patients. European Journal of Cancer Part B, Oral Oncology, 31B(4), 242-249.

Larson, J., Franzen-Dahlin, A., Billing, E., Arbin, M., Murray, V., \& Wredling, R. (2005). Predictors of quality of life among spouses of stroke patients during the first year after the stroke event. Scandinavian Journal of Caring Sciences, 19(4), 439-445.

Larsson, B. W. (1999). Patients' views on quality of care: Age effects and identification of patient profiles. Journal of Clinical Nursing, 8(6), 693-700.

Lewis, S. L., Bonner, P. N., Campbell, M. A., Cooper, C. L., \& Willard, A. (1994). Personality, stress, coping, and sense of coherence among nephrology nurses in dialysis settings. ANNA Journal, 21(6), 325-335.

Lewis, S. L., Campbell, M. A., Becktell, P. J., Cooper, C. L., Bonner, P. N., \& Hunt, W. C. (1992). Work stress, burnout, and sense of coherence among dialysis nurses. ANNA Journal, 19(6), 545-553.

Li, W., Leonhart, R., Schaefert, R., Zhao, X., Zhang, L., Wei, J., et al. (2015). Sense of coherence contributes to physical and mental health in general hospital patients in China. Psychology, Health and Medicine, 20(5), 614-622. https://doi.org/10.1080/13548506.2014 .952644

Linnen, H., Krampe, H., Neumann, T., Wei-Gerlach, E., Heinz, A., Wernecke, K. D., et al. (2011). Depression and essential health risk factors in surgical patients in the preoperative anaesthesiological assessment clinic. European Journal of Anaesthesiology, 28(10), 733-741.

Lithner, M., Johansson, J., Andersson, E., Jakobsson, U., Palmquist, I., \& Klefsgard, R. (2012). Perceived information after surgery for colorectal cancer-An explorative study. Colorectal Disease, 14(11), 1340-1350.

Lohmann, S., Strobl, R., Mueller, M., Huber, E. O., \& Grill, E. (2011). Psychosocial factors associated with the effects of physiotherapy in the acute hospital. Disability and Rehabilitation, 33(22-23), 2311-2321. 
Luhmann, N. (2011). Organisation und Entscheidung. Verlag für Sozialwissenschaften.

Lundberg, B., Hansson, L., Wentz, E., \& Bjorkman, T. (2009). Are stigma experiences among persons with mental illness, related to perceptions of self-esteem, empowerment and sense of coherence? Journal of Psychiatric and Mental Health Nursing, 16(6), 516-522.

Malagon-Aguilera, M. C., Fuentes-Pumarola, C., Suner-Soler, R., Bonmati-Tomas, A., Fernandez-Pena, R., \& Bosch-Farre, C. (2012). The sense of coherence among nurses. Enfermeria Clinica, 22(4), 214-218.

Malinauskiene, V., Leisyte, P., Romualdas, M., \& Kirtiklyte, K. (2011). Associations between self-rated health and psychosocial conditions, lifestyle factors and health resources among hospital nurses in Lithuania. Journal of Advanced Nursing, 67(11), 2383-2393.

Malinauskiene, V., Leisyte, P., \& Malinauskas, R. (2009). Psychosocial job characteristics, social support, and sense of coherence as determinants of mental health among nurses. Medicina (Kaunas, Lithuania), 45(11), 910-917.

Matsuura, E., Ohta, A., Kanegae, F., Haruda, Y., Ushiyama, O., Koarada, S., et al. (2003). Frequency and analysis of factors closely associated with the development of depressive symptoms in patients with scleroderma. Journal of Rheumatology, 30(8), 1782-1787.

Menzies, V. (2000). Depression in schizophrenia: Nursing care as a generalized resistance resource. Issues in Mental Health Nursing, 21(6), 605-617.

Michael, R., \& Jenkins, H. J. (2001). Recovery from work-related trauma by perioperative nurses: The effects of social and personal resources. Collegian, 8(3), 8-13.

Milz, H., \& Vang, J. (1989). Consultation on the role of health promotion in hospitals. Health Promotion International, 3(4), 425-427.

Mintzberg, H. (2012). Managing the myths of health care. World Hospitals and Health Services, 48(3), 4-7.

Mizuno, M., Kakuta, M., \& Inoue, Y. (2009). The effects of sense of coherence, demands of illness, and social support on quality of life after surgery in patients with gastrointestinal tract cancer. Oncology Nursing Forum, 36(3), E144-E152.

Mostofsky, D. I. (Ed.). (2014). The handbook of behavioral medicine. Wiley.

Myers, V., Drory, Y., \& Gerber, Y. (2011). Sense of coherence predicts post-myocardial infarction trajectory of leisure time physical activity: A prospective cohort study. BMC Public Health, 11, 708. https://doi.org/10.1186/1471-2458-11-708

Nilsson, P., Andersson, H. I., \& Ejlertsson, G. (2013). The work experience measurement scale (WEMS): A useful tool in workplace health promotion. Work, 45(3), 379-387.

Nordang, K., Hall-Lord, M. L., \& Farup, P. G. (2010). Burnout in health-care professionals during reorganizations and downsizing. A cohort study in nurses. BMC Nursing, 9, 8. https://doi. org/10.1186/1472-6955-9-8

Nordstrom, G., \& Lutzen, K. (1995). Acceptance of ostomy surgeryA Swedish pilot study. Scandinavian Journal of Caring Sciences, 9(1), 11-15.

Norekval, T. M., Fridlund, B., Moons, P., Nordrehaug, J. E., Saevareid, H. I., Wentzel-Larsen, T., et al. (2010). Sense of coherence-A determinant of quality of life over time in older female acute myocardial infarction survivors. Journal of Clinical Nursing, 19(5-6), 820-831.

Onega, L. L. (1991). A theoretical framework for psychiatric nursing practice. Journal of Advanced Nursing, 16(1), 68-73.

Orly, S., Rivka, B., Rivka, E., \& Dorit, S. E. (2012). Are cognitivebehavioral interventions effective in reducing occupational stress among nurses? Applied Nursing Research, 25(3), 152-157.

Paika, V., Almyroudi, A., Tomenson, B., Creed, F., Kampletsas, E. O., Siafaka, V., et al. (2010). Personality variables are associated with colorectal cancer patients' quality of life independent of psychological distress and disease severity. Psychooncology, 19(3), 273-282.
Palsson, M. B., Hallbert, I. R., Norberg, A., \& Isovaara, S. (1994). Systematic clinical supervision and its effects for nurses handling demanding care situations. Interviews with Swedish district nurses and hospital nurses in cancer care. Cancer Nursing, 17(5), 385-394.

Pelikan, J. M. (2007). Health promoting hospitals-Assessing developments in the network. Italian Journal of Public Health, 4, 261-270.

Pelikan, J. M., \& Dietscher, C. (2015). Gesundheitskompetenz im System der Krankenversorgung. Journal für Gesundheitsförderung, 2, 28-33.

Pelikan, J. M., Dietscher, C., Krajic, K., \& Nowak, P. (2005). Eighteen core strategies for health promoting hospitals. In O. Gröne \& M. Garcia-Barbero (Eds.), Health promotion in hospitals: Evidence and quality management (pp. 46-63). Copenhagen: World Health Organization-Regional Office for Europe. https://www.euro.who. int/_data/assets/pdf_file/0008/99827/E86220.pdf.

Pelikan, J. M., Gröne, O., \& Svane, J. K. (2011). The international HPH network-A short history of two decades of development. Clinical Health Promotion, 1(1), 32-36.

Pelikan, J. M., Krajic, K., \& Dietscher, C. (2001). The health promoting hospital (HPH): Concept and development. Patient Education and Counseling, 45(4), 239-243.

Pelikan, J. M., Schmied, H., \& Dietscher, C. (2014). Improving organizational health: The case of health promoting hospitals. In G. Bauer \& O. Hämmig (Eds.), Bridging occupational, organizational and public health. A transdisciplinary approach (pp. 133-153). Springer.

Pillay, B., Lee, S. J., Katona, L., De, B. S., Burney, S., \& Avery, S. (2014). A prospective study of the relationship between sense of coherence, depression, anxiety, and quality of life of haematopoietic stem cell transplant patients over time. Psychooncology, 24(2), $220-227$

Pusswald, G., Fleck, M., Haubenberger, D., Auff, E., \& Weber, G. (2009). What roll does the sense of coherence in coping with Morbus Parkinson play? Zeitschrift für Gerontologie und Geriatrie, 42(3), 220-227.

Quintard, B., Constant, A., Lakdja, F., \& Labeyrie-Lagardere, H. (2013). Factors predicting sexual functioning in patients 3 months after surgical procedures for breast cancer: The role of the sense of coherence. European Journal of Oncology Nursing, 18(1), 41-45.

Rabin, S., Shorer, Y., Nadav, M., Guez, J., Hertzanu, M., \& Shiber, A. (2011). Burnout among general hospital mental health professionals and the salutogenic approach. Israel Journal of Psychiatry and Related Sciences, 48(3), 175-181.

Reid, P. P., Kruger, N., DeMarco, R., Hanley, D., \& Conlin, G. (2004). Reshaping the practice environment: The importance of coherence. Journal of Nursing Administration, 34(4), 173-179.

Richardson, A., Adner, N., \& Nordstrom, G. (2001). Persons with insulin-dependent diabetes mellitus: Acceptance and coping ability. Journal of Advanced Nursing, 33(6), 758-763.

Ristner, G., Andersson, R., Johansson, L. M., Johansson, S. E., \& Ponzer, S. (2000). Sense of coherence and lack of control in relation to outcome after orthopaedic injuries. Injury, 31(10), 751-756.

Rock, D. (2008). SCARF: A brain-based model for collaborating with and influencing others. NeuroLeadership Journal, 1, 1-12.

Röthlin, F., Schmied, H., \& Dietscher, C. (2015). Organizational capacities for health promotion implementation: Results from an international hospital study. Health Promotion International, 30(2), 369-379.

Rudd, R., \& Anderson, J. E. (2006). The health literacy environment of hospitals and health centers. National Center for the Study of Adult Learning and Literacy and Health and Adult Literacy and Learning Initiative, Harvard School of Public Health.

Ruzyczka, E. W., Milaniak, I., Przybylowski, P., Wierzbicki, K., Siwinska, J., Hubner, F. K., et al. (2011). Depression and quality of life in terms of personal resources in heart transplant recipients. Transplantation Proceedings, 43(8), 3076-3081. 
Sack, M., Kunsebeck, H. W., \& Lamprecht, F. (1997). Sense of coherence and psychosomatic treatment outcome. An empirical study of salutogenesis. Psychotherapie, Psychosomatic, Medizinische Psychologie, 47(5), 149-155.

Sales, P. M., Carvalho, A. F., McIntyre, R. S., Pavlidis, N., \& Hyphantis, T. N. (2014). Psychosocial predictors of health outcomes in colorectal cancer: A comprehensive review. Cancer Treatment Reviews, 40(6), 800-809.

Schmitt, F., Santalahti, P., Saarelainen, S., Savonlahti, E., Romer, G., \& Piha, J. (2008). Cancer families with children: Factors associated with family functioning-A comparative study in Finland. Psychooncology, 17(4), 363-372.

Schneider, G., Driesch, G., Kruse, A., Wachter, M., Nehen, H. G., \& Heuft, G. (2004). What influences self-perception of health in the elderly? The role of objective health condition, subjective Well-being and sense of coherence. Archives of Gerontology and Geriatrics, 39(3), 227-237.

Schneider, G., Heuft, G., \& Hockmann, J. (2011). Determinants of social anxiety and social avoidance in psoriasis outpatients. Journal of the European Academy of Dermatology and Venereology, 27(3), 383-386.

Schnyder, U., Morgeli, H., Nigg, C., Klaghofer, R., Renner, N., Trentz, O., et al. (2000). Early psychological reactions to life-threatening injuries. Critical Care Medicine, 28(1), 86-92.

Schult, M. L., Soderback, I., \& Jacobs, K. (2000). The sense-ofcoherence and the capability of performing daily occupations in persons with chronic pain. Work, 15(3), 189-201.

Siglen, E., Bjorvatn, C., Engebretsen, L. F., Berglund, G., \& Natvig, G. K. (2007). The influence of cancer-related distress and sense of coherence on anxiety and depression in patients with hereditary cancer: A study of patients' sense of coherence 6 months after genetic counseling. Journal of Genetic Counseling, 16(5), 607-615.

Silarova, B., Nagyova, I., Rosenberger, J., Studencan, M., Ondusova, D., Reijneveld, S. A., et al. (2012). Sense of coherence as an independent predictor of health-related quality of life among coronary heart disease patients. Quality of Life Research, 21(10), 1863-1871.

Silarova, B., Nagyova, I., Van Dijk, J. P., Rosenberger, J., \& Reijneveld, S. A. (2013). Anxiety and sense of coherence in Roma and nonRoma coronary heart disease patients. Ethnicity and Health, 19(5), 500-511.

Sinikallio, S., Aalto, T., Airaksinen, O., Herno, A., Kroger, H., Savolainen, S., et al. (2006). Depression and associated factors in patients with lumbar spinal stenosis. Disability and Rehabilitation, 28(7), 415-422.

Sjostrom, N., Hetta, J., \& Waern, M. (2012). Sense of coherence and suicidality in suicide attempters: A prospective study. Journal of Psychiatric and Mental Health Nursing, 19(1), 62-69.

Sjostrom, H., Langius-Eklof, A., \& Hjertberg, R. (2004). Well-being and sense of coherence during pregnancy. Acta Obstetricia et Gynecologica Scandinavica, 83(12), 1112-1118.

Skarsater, I., Langius, A., Agren, H., Haggstrom, L., \& Dencker, K. (2005). Sense of coherence and social support in relation to recovery in first-episode patients with major depression: A one-year prospective study. International Journal of Mental Health Nursing, 14(4), 258-264.

Soderhamn, U., Bachrach-Lindstrom, M., \& Ek, A. C. (2008). Self-care ability and sense of coherence in older nutritional at-risk patients. European Journal of Clinical Nutrition, 62(1), 96-103.

Soderman, A. C., Bergenius, J., Bagger-Sjoback, D., Tjell, C., \& Langius, A. (2001). Patients' subjective evaluations of quality of life related to disease-specific symptoms, sense of coherence, and treatment in Meniere's disease. Otology \& Neurotology, 22(4), 526-533.

Sørensen, K., Pelikan, J. M., Röthlin, F., Ganahl, K., Slonska, Z., Doyle, G., et al. (2015). Health literacy in Europe: Comparative results of the European health literacy survey (HLS-EU). European Journal of Public Health, 25(6), 1053-1058. https://doi.org/10.1093/ eurpub/ckv043

Spadoti Dantas, R. A., Silva, F. S., \& Ciol, M. A. (2014). Psychometric properties of the Brazilian Portuguese versions of the 29- and 13-item scales of the Antonovsky's sense of coherence (SOC-29 and SOC-13) evaluated in Brazilian cardiac patients. Journal of Clinical Nursing, 23(1-2), 156-165.

Stramrood, C. A., Paarlberg, K. M., Huis In't Veld, E. M., Berger, L. W., Vingerhoets, A. J., Schultz, W. C., et al. (2011). Posttraumatic stress following childbirth in homelike- and hospital settings. Journal of Psychosomatic Obstetrics and Gynaecology, 32(2), 88-97.

Stromsvik, N., Nordin, K., Berglund, G., Engebretsen, L. F., Hansson, M. G., \& Gjengedal, E. (2007). Living with multiple endocrine neoplasia type 1: Decent care-insufficient medical and genetic information-A qualitative study of MEN 1 patients in a Swedish hospital. Journal of Genetic Counseling, 16(1), 105-117.

Swenne, C. L., \& Skytt, B. (2013). The ward round-Patient experiences and barriers to participation. Scandinavian Journal of Caring Sciences, 28(2), 297-304.

Takeuchi, T., \& Yamazaki, Y. (2010). Relationship between workfamily conflict and a sense of coherence among Japanese registered nurses. Japan Journal of Nursing Science, 7(2), 158-168.

Tang, S. T., Cheng, C. C., Lee, K. C., Chen, C. H., \& Liu, L. N. (2013), Mediating effects of sense of coherence on family caregivers' depressive distress while caring for terminally ill cancer patients. Cancer Nursing, 36(6), E25-E33.

Tishelman, C., Taube, A., \& Sachs, L. (1991). Self-reported symptom distress in cancer patients: Reflections of disease, illness or sickness? Social Science \& Medicine, 33(11), 1229-1240.

Tistad, M., Tham, K., von Koch, L., \& Ytterberg, C. (2012). Unfulfilled rehabilitation needs and dissatisfaction with care 12 months after a stroke: An explorative observational study. BMC Neurology, 12, 40.

Torrati, F. G., Gois, C. F., \& Dantas, R. A. (2010). Strategy in the care of cardiac surgical patients: Evaluation of the sense of coherence. Revista da Escola Enfermagem da USP, 44(3), 739-744.

Tschan, R., Best, C., Beutel, M. E., Knebel, A., Wiltink, J., Dieterich, M., et al. (2011). Patients' psychological well-being and resilient coping protect from secondary somatoform vertigo and dizziness (SVD) 1 year after vestibular disease. Journal of Neurology, 258(1), 104-112.

Tselebis, A., Moulou, A., \& Ilias, I. (2001). Burnout versus depression and sense of coherence: Study of Greek nursing staff. Nursing and Health Sciences, 3(2), 69-71.

Tzuh, T. S., \& Li, C. Y. (2008). The important role of sense of coherence in relation to depressive symptoms for Taiwanese family caregivers of cancer patients at the end of life. Journal of Psychosomatic Research, 64(2), 195-203.

Ulrich, R. S., Berry, L. L., Quan, X., \& Parish, J. T. (2010). A conceptual framework for the domain of evidence-based design. HERD, $4(1), 95-114$.

Veenstra, M., \& Hofoss, D. (2003). Patient experiences with information in a hospital setting: A multilevel approach. Medical Care, 41(4), 490-499.

Ventegodt, S., Kandel, I., \& Merrick, J. (2007). First do no harm: An analysis of the risk aspects and side effects of clinical holistic medicine compared with standard psychiatric biomedical treatment. ScientificWorldJournal, 7, 1810-1820.

Ventegodt, S., Merrick, E., \& Merrick, J. (2006). Clinical holistic medicine: The dean Ornish program ("opening the heart") in cardiovascular disease. ScientificWorldJournal, 6, 1977-1984.

Ventegodt, S., Thegler, S., Andreasen, T., Struve, F., Enevoldsen, L., Bassaine, L., et al. (2007). Clinical holistic medicine (mindful, short-term psychodynamic psychotherapy complemented with bodywork) in the treatment of experienced mental illness. ScientificWorldJournal, 7, 306-309. 
Wang, Q., Hay, M., Clarke, D., \& Menahem, S. (2012). The prevalence and predictors of anxiety and depression in adolescents with heart disease. Journal of Pediatrics, 161(5), 943-946.

Warwick, M., Gallagher, R., Chenoweth, L., \& Stein-Parbury, J. (2010). Self-management and symptom monitoring among older adults with chronic obstructive pulmonary disease. Journal of Advanced Nursing, 66(4), 784-793.

Wikblad, K. F., \& Montin, K. R. (1992). Coping with a chronic disease. The Diabetes Educator, 18(4), 316-320.

World Health Organization. (1986). Ottawa charter for health promotion: Towards a new public health. World Health Organization.

World Health Organization-Regional Office for Europe. (1991). The Budapest declaration on health promoting hospitals. World Health Organization-Regional Office for Europe.
World Health Organization-Regional Office for Europe. (1997). The Vienna recommendations on health promoting hospitals. World Health Organization-Regional Office for Europe.

World Health Organization-Regional Office for Europe. (2013). Health 2020. A European policy framework and strategy for the 21st century. World Health Organization-Regional Office for Europe.

Wrzesniewski, K., \& Wlodarczyk, D. (2012). Sense of coherence as a personality predictor of the quality of life in men and women after myocardial infarction. Kardiologia Polska, 70(2), 157-163.

Yang, X., Wang, L., He, J., Ge, C., Chang, Y., Fu, J., et al. (2012). Factors related to depressive symptoms among Chinese caregivers of cancer patients. Psychooncology, 21(10), 1063-1070.

Open Access This chapter is licensed under the terms of the Creative Commons Attribution 4.0 International License (http://creativecommons. org/licenses/by/4.0/), which permits use, sharing, adaptation, distribution and reproduction in any medium or format, as long as you give appropriate credit to the original author(s) and the source, provide a link to the Creative Commons license and indicate if changes were made.

The images or other third party material in this chapter are included in the chapter's Creative Commons license, unless indicated otherwise in a credit line to the material. If material is not included in the chapter's Creative Commons license and your intended use is not permitted by statutory regulation or exceeds the permitted use, you will need to obtain permission directly from the copyright holder. 